Universidad de Lima

Escuela de Posgrado

Maestría en Administración de Negocios

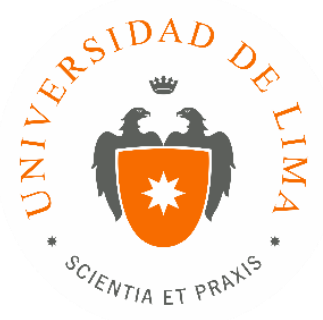

\title{
Proyecto para la implementación de una empresa capacitadora en manejo defensivo y económico en el transporte de carga y pasajeros
}

\author{
Tesis para optar por el título profesional del Grado Académico de Maestro en \\ Administración de Negocios
}

Roger Felix Arrieta Gallardo

20021927

\author{
Asesor \\ Edmundo Casavilca \\ Lima - Perú \\ Diciembre de 2017
}




\section{PROYECTO PARA LA IMPLEMENTACIÓN DE UNA EMPRESA CAPACITADORA EN MANEJO DEFENSIVO Y ECONÓMICO EN EL TRANSPORTE DE CARGA Y DE PASAJEROS}




\section{TABLA DE CONTENIDO}

\section{CAPÍTULO I: ASPECTOS GENERALES DEL NEGOCIO.......................17}

1.1 Presentación de la empresa.........................................18

1.2 Marco teórico y mercado (benchmark y mejores prácticas

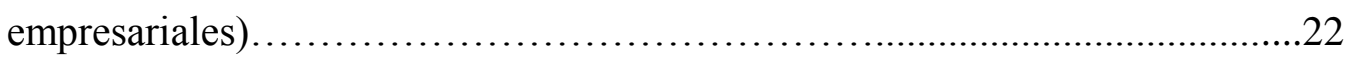

1.3 Motivación del proyecto........................................30

1.4 Percepción de la necesidad: análisis problema-solución.................31

1.5 Descripción de la idea y la oportunidad...............................32

1.6 Justificación del atractivo de la propuesta............................33

$1.7 \quad$ Estrategia inicial y objetivos de alcance................................34

$1.8 \quad$ Impacto comercial y responsabilidad social...........................34

CAPÍTULO II: IDEA, INVESTIGACIÓN Y VALIDACIÓN DE SOLUCIÓN....36

2.1 Diseño y metodología de la investigación.............................36

2.2 Validación de

hipótesis................................................................. 36

2.3 Validación de la

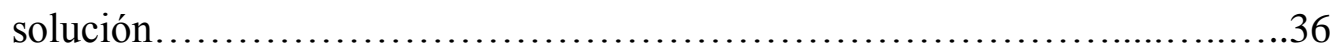

2.4 Muestreo

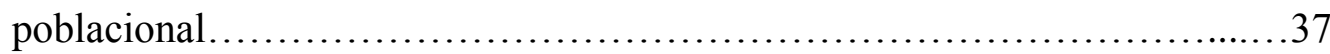

2.5 Análisis de tendencias y patrones................................39

2.6 Canvas del modelo de negocio..................................40

2.7 Conclusiones................................................43

CAPÍTULO III: PLANEAMIENTO ESTRATÉGICO............................44

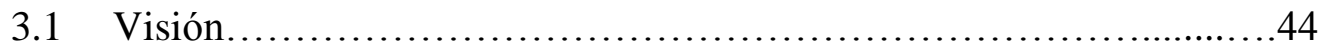

3.2 Misión........................................................... 44 
3.3 Valores y ética.

3.4 Cultura organizacional..........................................45

3.5 Objetivos estratégicos..........................................45

3.6 Análisis externo: político, legal, circunstancial, económico, geográfico, social, demográfico, cultural, tecnológico, ambiental (pestel).

3.7 Análisis interno: competidores potenciales, clientes, proveedores, productos sustitutos, barreras de entrada... .46

3.8 Análisis sectorial e identificación de riesgos y amenazas. Análisis foda. .50

3.9 Estrategia de éxito (Foda cruzado) .51

CAPÍTULO IV: PLAN DE MARKETING. .52

4.1 Planteamiento de objetivos generales de marketing .................52

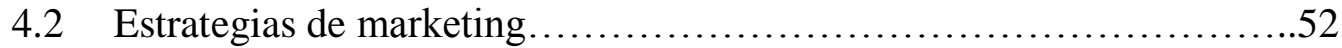

$4.3 \quad$ Mercado objetivo................................................53

4.4 Desarrollo y estrategia del marketing mix..........................56

4.4.1 Política de gestión del cliente....................................57

4.4.2 Estrategia de producto: especificaciones, calidad, variabilidad y

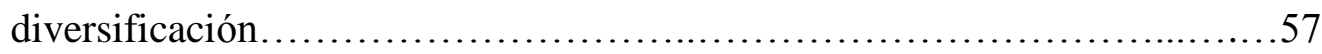

4.4.3 Estrategia de precios: análisis de costos y precios...................57

4.4.4 Política comercial.................................................58

4.4.5 Estrategia comunicacional y canal.............................58

4.4.6 Estrategia de distribución...........................................59

4.5 Plan de ventas (objetivos anuales, alcance de la oferta) y proyección de la demanda (crecimiento y desarrollo)......................................59

CAPÍTULO V: PLAN DE OPERACIONES.....................................62

5.1 Políticas operacionales........................................62

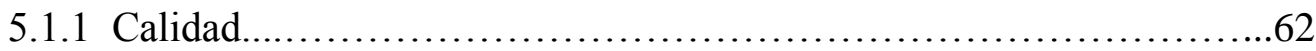


5.1.2 Procesos .62

5.1.3 Planificación.....................................................63

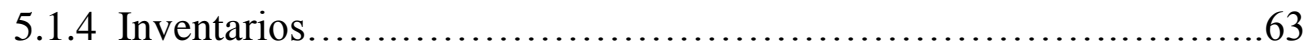

5.2 Equipos, actividades y procesos..............................63

5.2.1 Localización, diseño y capacidad de instalaciones...................63

5.2.2 Equipos de trabajo y apoyos...................................64

5.2.3 Gestión de proveedores, compras y stock..........................65

5.2.4 Tercerización o integración de procesos...........................65

5.2.5 Implementación de las actividades por fases cadena de valor..........65

5.2.6 Proceso de presentación de servicio.................................66

5.2.7 Políticas de transformación de la actividad...........................66

5.2.8 Flujograma de la actividad y diagrama de decisiones................66

5.2.9 Balance scorecard: control de gestión por indicadores...............71

5.2.10 Marco legal.................................................71

\section{CAPÍTULO VI: ESTRUCTURA ORGANIZACIONAL Y RECURSOS

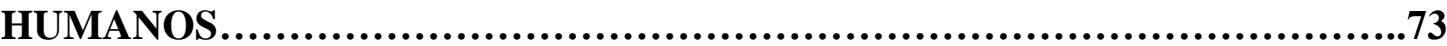

6.1 Objetivos organizacionales................................... 73

6.1.1 Naturaleza de la organización......................................74

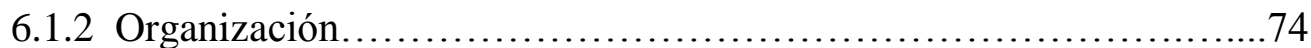

6.1.3 Diseño estructural por proyectos......................................74

6.2 Diseño de puestos y responsabilidades.............................74

6.3 Políticas organizacionales...................................... 74

6.3.1 Políticas de fidelización de capacitadores............................75

6.3.2 Certificación internacional de conductores...........................75

6.4 Gestión del talento.................................................

6.4.1 Selección y contratación.........................................75 
6.4.2 Remuneraciones y desempeño................................76

6.4.3 Empowerment y reconocimiento................................77

6.4.4 Capacitación, motivación y desarrollo...............................78

6.5 Estructura de gastos de recursos humanos..........................78

CAPITULO VII: PLAN ECONÓMICO-FINANCIERO...........................79

$7.1 \quad$ Supuestos.................................................. 79

7.2 Plan de inversiones........................................... 80

7.3 Activos y depreciación........................................81

7.4 Capital de trabajo.............................................81

7.5 Fuentes de financiamiento y amortización..........................81

7.6 Balances previsionales.......................................81

7.7 Cuentas de exploración previsionales (ggpp)......................82

7.8 Proyección de ventas y flujo de tesorería (cash flow)................83

7.9 Políticas de aplicación de resultados...............................84

7.10 Tasa de descuento del accionista..................................84

7.11 Indicadores de rentabilidad representativos........................85

7.12 Análisis de viabilidad y rentabilidad financiera.......................87

7.13 Análisis de riesgo............................................87

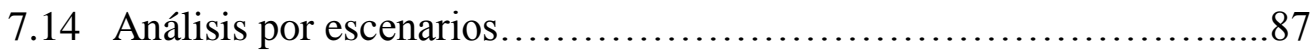

7.15 Principales riesgos del proyecto.................................. 88

7.16 Plan de contingencias y disolución................................89

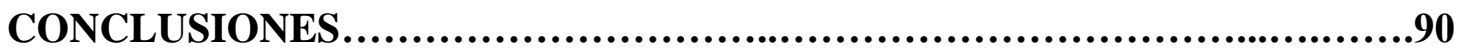




\section{ÍNDICE DE TABLAS}

TABLA 1.1 PARQUE VEHICULAR DE EMPRESAS DE TRANSPORTE DE PASAJEROS POR CARRETERA, SEGÚN ÁMBITO Y CLASE DE VEHÍCULO, 2005-2016.

TABLA 1.2 PARQUE VEHICULAR DE EMPRESA DE TRANSPORTE DE PASAJEROS POR CARRETERA, SEGÚN ÁMBITO Y MODALIDAD DEL SERVICIO, 2005-2016 .17

TABLA 1.3 PARQUE VEHICULAR DE EMPRESA DE TRANSPORTE DE CARGA, SEGÚN ÁMBITO Y CLASE DE VEHÍCULO, 2005-2016 (EN UNIDADES) .18

TABLA 1.4 LICENCIAS DE CONDUCIR A NIVEL NACIONAL AIII, 20072016 .

TABLA 1.5 ACCIDENTES DE TRÁNSITO FATALES Y NO FATALES POR AÑO, SEGÚN CLASE: $2007-2016$. .26

TABLA 1.6 PROBLEMAS Y SOLUCIONES DE LA NECESIDAD PLANTEADA .29

TABLA 2.1 CANTIDAD DE UNIDADES DE CARGA DE PASAJEROS Y LICENCIAS DE CONDUCIR. 34

TABLA 2.2 EMPRESAS AUTORIZADAS: TRANSPORTE DE CARGA.........35

TABLA 2.3 EMPRESAS AUTORIZADAS: TRANSPORTE DE PASAJEROS...35

TABLA 2.4 CANVAS DEL MODELO DE NEGOCIO ........................... 38

TABLA 3.1 ANÁLISIS PESTEL............................................45

TABLA 3.2 ESTRATEGIA DEL FODA CRUZADO.........................48

TABLA 4.1 PROYECCIÓN DE LA DEMANDA...............................43

TABLA 5.1 RANKING DE FACTORES PARA LA UBICACIÓN.................57

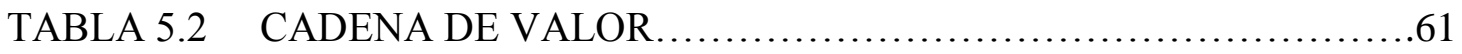


TABLA 5.3 ACTIVIDADES REQUERIDAS PARA LA PUESTA EN MARCHA..63

TABLA 5.4 TIEMPOS REQUERIDOS PARA LA PUESTA EN MARCHA......63

TABLA 6.1 REMUNERACIONES DEL PERSONAL..........................71

TABLA 7.1 PLAN DE REQUERIMIENTOS DE ACTIVO FIJO PARA LAS OPERACIONES....................................................... 75

TABLA 7.2 PLAN DE INVERSIONES REQUERIDO PARA EL NEGOCIO........75

TABLA 7.3 AMORTIZACIÓN Y DEPRECIACIÓN...............................76

TABLA 7.4 BALANCE GENERAL DURANTE HORIZONTE DE ANÁLISIS...76

TABLA 7.5 ESTADO DE RESULTADOS ...................................... 77

TABLA 7.6 PROYECCIONES DE VENTAS ..................................78

TABLA 7.7 FLUJO DE CAJA DEL FUTURO NEGOCIO ......................79

TABLA 7.8 REPARTICIÓN DE UTILIDADES...............................79

TABLA 7.9 CÁlCULO DE LA TASA DE DESCUENTO DE LOS ACCIONISTAS ......................................................... 80

TABLA 7.10 DETERMINACIÓN DEL VAN Y TIR .............................80

TABLA 7.11 CÁLCULO DE ROE, ROA Y ROI................................81

TABLA 7.12 CÁLCULO DEL PUNTO DE EQUILIBRIO.........................81

TABLA 7.13 PROYECCIÓN DE VENTAS - ESCENARIOS.....................83 


\section{ÍNDICE DE FIGURAS}

FIGURA 1.1 ACCIDENTES, FALLECIDOS Y HERIDOS ENTRE EL AÑO 2015 Y 2016 DEL 1ERO DE ENERO AL 8 DE AGOSTO. .15

FIGURA 1.2 ACCIDENTES DE TRÁNSITO CON DAÑOS PERSONALES DE VEHÍCULOS DE SERVICIO DE TRANSPORTE TERRESTRE DE PERSONAS, CARGA Y MERCANCÍAS, POR NÚMERO DE ACCIDENTES, FALLECIDOS Y HERIDOS .22

FIGURA 1.3 ACCIDENTES DE TRÁNSITO CON DAÑOS PERSONALES DE VEHÍCULOS DE SERVICIO DE TRANSPORTE TERRESTRE DE PERSONAS, CARGA Y MERCANCÍAS, VEHÍCULOS PARTICIPANTES SEGÚN CLASIFICACIÓN. .23

FIGURA 1.4 ACCIDENTES DE TRÁNSITO CON DAÑOS PERSONALES DE VEHÍCULOS DE SERVICIO DE TRANSPORTE TERRESTRE DE PERSONAS, CARGAS Y MERCANCÍAS, PARTICIPACIÓN DE VEHÍCULOS DE MEJOR CAPACIDAD. 24

FIGURA 1.5 ACCIDENTES DE TRÁNSITO CON DAÑOS PERSONALES DE VEHÍCULOS DE SERVICIO DE TRANSPORTE TERRESTRE DE PERSONAS, CARGAS Y MERCANCÍAS, SEGÚN HORARIO DE INCIDENCIAS (PERIODOS DE 2 HORAS). 25

FIGURA 1.6 ACCIDENTE VEHICULAR DE UN BUS DE PASAJEROS. 27

FIGURA 5.1 REPRESENTACIÓN DEL DIAGRAMA VECTORIAL O RED......64 FIGURA 5.2 REPRESENTACIÓN DEL DIAGRAMA VECTORIAL O RED CON TIEMPOS. .65

FIGURA 5.3 CRONOGRAMA DEL PROYECTO EN MICROSOFT PROJECT..66 FIGURA 7.1 ORGANIGRAMA DE LA EMPRESA. .69 


\section{ÍNDICE DE ANEXOS}

ANEXO I: PERFILES Y FUNCIONES DEL PERSONAL $\ldots \ldots \ldots \ldots \ldots \ldots \ldots \ldots . . \ldots 9$

ANEXO II: FORMATO DE ENTREVISTA DE PROFUNDIDAD ..................97

ANEXO III: RESULTADOS DE LA ENTREVISTAS A PROFUNDIDAD..........98 


\section{RESUMEN EJECUTIVO}

Actualmente en el Perú, el número de accidentes de tránsito en carreteras pasa las 500 muertes por año. El desconocimiento, la imprudencia, el exceso de confianza son algunos de los motivos que originan estas tragedias.

Las causas de estos accidentes indican que existe entre un $95 \%$ y $98 \%$ por falla humana, solo la diferencia es por falla técnica; es decir, si trabajamos y nos enfocamos en la persona, podemos disminuir esta cantidad de accidentes y desgracias. Si bien no tenemos la cifra exacta de cuántos de estos accidentes son por falta de capacitación, tenemos la certeza de que trabajando con las personas tendremos una caída en estos indicadores.

Este trabajo desarrollará la implementación de una empresa que capacitará a los conductores de transporte de carga y de pasajeros en seguridad vial, manejo defensivo, conocimiento de la unidad, manejo económico, entre otros; y, por otro lado, en la empresa-cliente se desarrollarán consumos de combustibles, hojas de rutas, itinerarios, procesos de selección, inducción de conductores, entre otros. Lo antes mencionado ayudará a reducir los accidentes de tránsito por causas personales, así como a la disminución de los costos de transporte por mejor conservación de la unidad, menor consumo de combustible y reducción de todos los gastos que originan los accidentes.

Nuestro mercado potencial está conformado por todas aquellas empresas que tienen un número mayor a 10 unidades, y se levantará la información del servicio propuesto mediante entrevistas a propietarios, gerentes de transporte y jefes de transporte para poder afinar el servicio y entregar a los clientes los servicios requeridos por el mercado.

En nuestro país, actualmente no existen empresas que den este servicio de manera integral. Si bien existen empresas que dan charlas de seguridad y manejo defensivo, nuestro servicio implica la capacitación de los conductores en el lugar; es decir, se realizarán viajes con los conductores en capacitación real, y podrán realizar viajes hasta de 12 horas a diferentes destinos del Perú. Por otro lado, soportaremos a las empresas de transporte en otros servicios requeridos por ellos. Finalmente, validaremos económicamente la viabilidad del presente proyecto mediante análisis del TIR y VAN. 


\section{CAPÍTULO I: ASPECTOS GENERALES DEL NEGOCIO}

En este capítulo 1 analizaremos la necesidad de las empresas de transporte terrestre de pasajeros y de carga sobre la necesidad de capacitar a los conductores en manejo defensivo y manejo económico. Esto, debido principalmente al alto número de accidentes ocurridos en carretera que conllevan a la pérdida de vidas humanas, daños civiles y en algunos casos, daños al medio ambiente; así como el alto costo en el consumo de combustible y desgaste prematuro del motor de la unidad que hace que sus operaciones pierdan eficiencia

Para entender la magnitud de la accidentabilidad, en el año 2016, en el Perú tuvimos una tasa de 489 muertos por accidentes de tránsito (Superintendencia de Transporte Terrestre de Personas, 2016), mientras que, en el año 2015, ocurrieron 139 accidentes que dejaron 285 muertos y 1653 heridos según la misma fuente.

Estas cifras nos dan una idea de lo accidentado y mortal que puede significar el transporte por carretera. En la Figura $N^{\circ} 1.1$ comparamos los accidentes ocurridos entre el año 2015 y 2016, del primero de enero al 8 de agosto de cada año, podemos apreciar el impacto que tiene en la sociedad este tipo de eventos indeseados. También podemos apreciar la cantidad de accidentes que se presentan tanto en la Panamericana Norte como en la Panamericana Sur, así como en las carreteras de penetración. 
Figura $\mathrm{N}^{\circ}$ 1.1: Accidentes, fallecidos y heridos entre el año 2015 y 2016 del 1 ero de enero al 8 de agosto

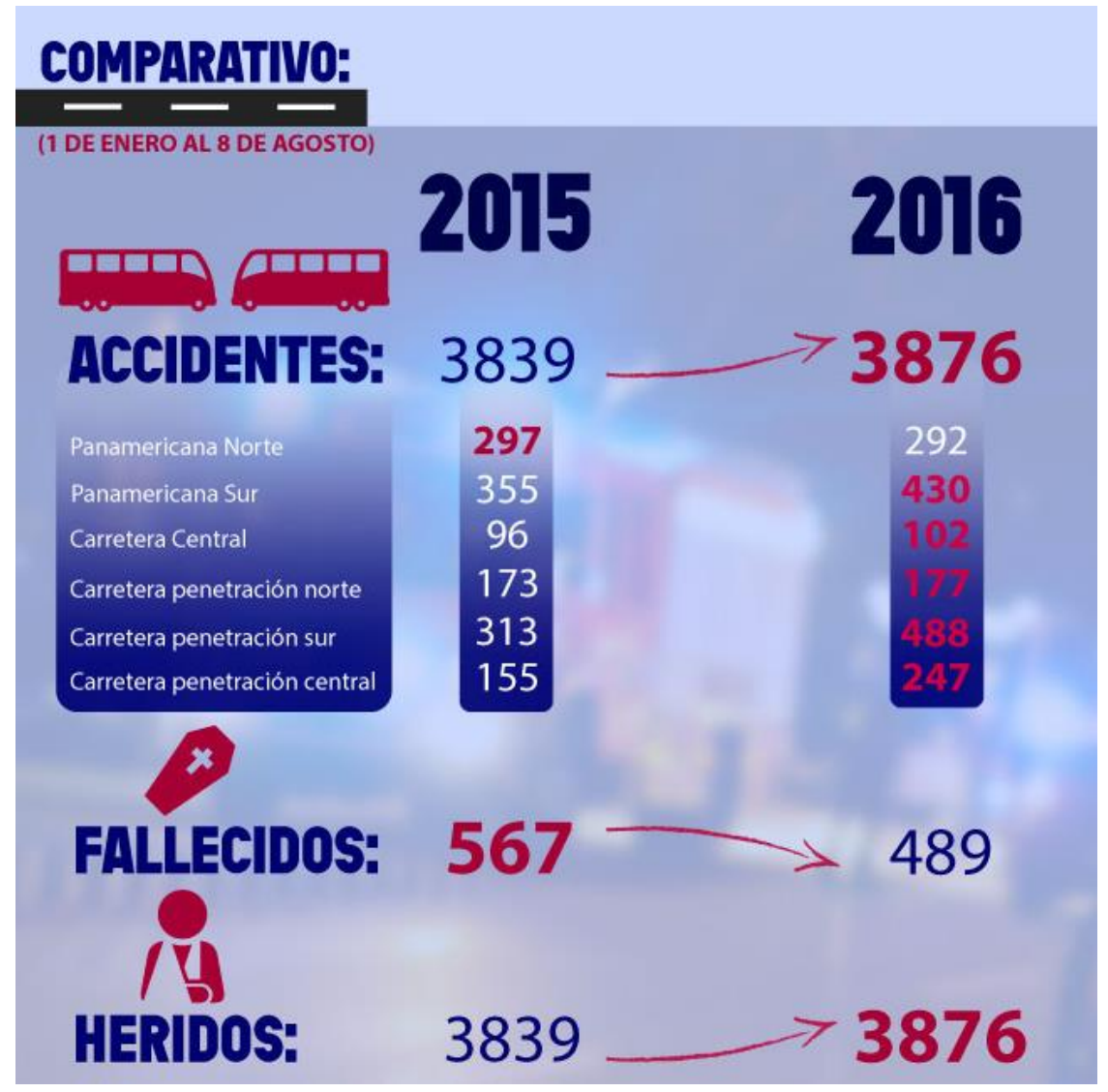

Fuente: SUTRAN

Por otro lado, analizaremos también por qué es atractivo para las empresas de transporte invertir en capacitación a los conductores: las pérdidas económicas que se pueden reducir, la conservación de los activos (buses, tractos, semirremolque, etc.), la reducción de los sobrecostos en consumo de combustible, reducción de problemas legales, entre otros, son algunos de los motivos por los que las empresas de transporte deben invertir en este tipo de capacitaciones, pues traerán beneficios para todos los actores en este proceso.

\subsection{Presentación de la empresa}

La empresa que desarrollaremos e implementaremos será una organización que tendrá como función principal la de capacitar in situ a conductores en manejo defensivo y económico, asesorar a las empresas de transporte sobre desarrollo de hojas de ruta, itinerarios, procesos de selección, inducción de conductores nuevos, entre otros. 
Este tipo de servicios es una necesidad en el mercado nacional actual, ya que no existen empresas peruanas que realicen todo el servicio. Si bien existen empresas de capacitación de conductores en aula que desarrollan hojas de rutas, otras calculan los estimados de consumo de combustible por unidad bajo ciertas condiciones en ruta, con cierta cantidad de toneladas de carga y diferentes tipos de caminos y distancias; sin embargo, no existen empresas que ofrezcan todo esto de manera consolidada y logre esa sinergia de todas las actividades.

Nuestra empresa estará formada principalmente por conductores capacitadores, con habilidades de comunicación, pedagogía y conocimiento técnico de la unidad de transporte y conducción; por eso, pasarán por capacitaciones y pruebas exhaustivas sobre conocimiento en manejo, comunicación interpersonal, negociación, andragogía, empoderamiento, entre otras habilidades necesarias para crear el perfil que buscamos desarrollar en nuestras labores con la calidad deseada. En el futuro se buscarán certificaciones internacionales.

Por otro lado, como un apoyo a la sociedad, desarrollaremos capacitaciones gratuitas básicas a empresas de transporte de mototaxi (parte responsable en los accidentes vehiculares) que también tienen una gran incidencia de fallecidos en estos eventos. Estas capacitaciones no serán parte de nuestro servicio, serán capacitaciones de concientización.

Para tener una idea inicial de nuestro mercado potencial, a continuación presentamos algunos cuadros del Instituto Nacional de Estadística e Informática INEI (2016), donde apreciamos en la Tabla $\mathrm{N}^{\circ} 1.1$ la cantidad de unidades registradas para el transporte de pasajeros por carretera y los omnibuses registrados. Estos suman un total de 10,183 unidades, parte de nuestro mercado objetivo.

En la Tabla $\mathrm{N}^{\circ} 1.2$ tenemos la cantidad de empresas autorizadas de transporte de pasajeros hasta el año 2016 y nuestro mercado objetivo estará conformado por transporte de pasajeros interdepartamental que suman 489. 
Tabla $\mathrm{N}^{\circ}$ 1.1: Parque vehicular de empresas de transporte de pasajeros por carretera, según ámbito y clase de vehículo, 2007-2016 (en unidades)

\begin{tabular}{|lrrrrrrrrrr}
\hline $\begin{array}{l}\text { ÁMBITO Y CLASE } \\
\text { DE VEHÍCULO }\end{array}$ & $\mathbf{2 0 0 7}$ & $\mathbf{2 0 0 8}$ & $\mathbf{2 0 0 9}$ & $\mathbf{2 0 1 0}$ & $\mathbf{2 0 1 1}$ & $\mathbf{2 0 1 2}$ & $\mathbf{2 0 1 3}$ & $\mathbf{2 0 1 4}$ & $\mathbf{2 0 1 5}$ & $\mathbf{2 0 1 6}$ \\
\hline TOTAL & $\mathbf{5 3 4 1}$ & $\mathbf{6 3 4 2}$ & $\mathbf{6 9 1 6}$ & $\mathbf{7 9 7 3}$ & $\mathbf{7 7 3 7}$ & $\mathbf{8 4 4 8}$ & $\mathbf{9 1 9 0}$ & $\mathbf{9 9 3 2}$ & $\mathbf{1 1 0 5 8}$ & $\mathbf{1 2 6 2 1}$ \\
\hline Nacional & $\mathbf{5 2 7 5}$ & $\mathbf{6 2 7 0}$ & $\mathbf{6 7 6 0}$ & $\mathbf{7 6 5 5}$ & $\mathbf{7 5 6 4}$ & $\mathbf{8 3 0 5}$ & $\mathbf{9 0 4 2}$ & $\mathbf{9 8 0 2}$ & $\mathbf{1 0 9 5 4}$ & $\mathbf{1 2 4 9 6}$ \\
Automóvil & 8 & 16 & 6 & 6 & 6 & 9 & 9 & 6 & 9 & 8 \\
Station Wagon & 149 & 172 & 153 & 108 & 9 & 26 & 7 & 5 & 0 & 4 \\
Camioneta Rural & 247 & 516 & 792 & 1185 & 1573 & 1797 & 1775 & 1936 & 2058 & 2301 \\
Omnibus & 4871 & 5566 & 5809 & 6356 & 5976 & 6473 & 7251 & 7855 & 8887 & 10183 \\
Internacional & $\mathbf{6 6}$ & $\mathbf{7 2}$ & $\mathbf{1 5 6}$ & $\mathbf{3 1 8}$ & $\mathbf{1 7 3}$ & $\mathbf{1 4 3}$ & $\mathbf{1 4 8}$ & $\mathbf{1 3 0}$ & $\mathbf{1 0 4}$ & $\mathbf{1 2 5}$ \\
Omnibus & 66 & 72 & 156 & 318 & 173 & 143 & 148 & 130 & 104 & 125 \\
\hline Fuente: MTC - Dirección General de Transporte Terrestre & & & & & &
\end{tabular}

Elaboración: MTC - OGPP - Oficina de Estadística

Tabla $\mathrm{N}^{\circ} 1.2$-Empresa autorizadas de Transporte de pasajeros por carretera, según ámbito y modalidad de servicio, 2007-2016 (número de empresas)

\begin{tabular}{|lrrrrrrrrrr}
\hline $\begin{array}{l}\text { ÁMBITO Y MODALIDAD } \\
\text { DE SERVICIO }\end{array}$ & $\mathbf{2 0 0 7}$ & $\mathbf{2 0 0 8}$ & $\mathbf{2 0 0 9}$ & $\mathbf{2 0 1 0}$ & $\mathbf{2 0 1 1}$ & $\mathbf{2 0 1 2}$ & $\mathbf{2 0 1 3}$ & $\mathbf{2 0 1 4}$ & $\mathbf{2 0 1 5}$ & $\mathbf{2 0 1 6}$ \\
\hline TOTAL & $\mathbf{5 9 7}$ & $\mathbf{7 7 7}$ & $\mathbf{9 1 4}$ & $\mathbf{9 5 2}$ & $\mathbf{1 0 2 0}$ & $\mathbf{1 1 2 4}$ & $\mathbf{1 2 5 5}$ & $\mathbf{1 5 7 4}$ & $\mathbf{1 8 3 8}$ & $\mathbf{2 3 0 1}$ \\
\hline Nacional & $\mathbf{5 9 0}$ & $\mathbf{7 6 9}$ & $\mathbf{9 0 4}$ & $\mathbf{9 4 3}$ & $\mathbf{1 0 1 1}$ & $\mathbf{1 1 1 5}$ & $\mathbf{1 2 4 3}$ & $\mathbf{1 5 6 1}$ & $\mathbf{1 8 2 6}$ & $\mathbf{2 2 8 9}$ \\
$\quad$ Inter Departamental & 371 & 348 & 344 & 341 & 337 & 356 & 381 & 425 & 434 & 485 \\
Intra Departamental & 22 & 19 & 18 & 17 & 17 & 14 & 15 & 13 & 12 & 4 \\
Turístico Nacional & 155 & 323 & 437 & 471 & 507 & 549 & 572 & 712 & 837 & 1,055 \\
Turístico Departamental & 2 & - & - & - & - & - & - & - & - \\
Comunal & - & - & 1 & 1 & 1 & 1 & 1 & - & - \\
Excepcional & 12 & 14 & 13 & 8 & 3 & 2 & 2 & 2 & - \\
Trabajadores & 28 & 65 & 91 & 105 & 93 & 111 & 153 & 218 & 276 & 344 \\
Servicio Social & - & - & - & - & - & - & - & - & - \\
Privado & - & - & - & - & 53 & 82 & 119 & 191 & 267 & 399 \\
Internacional & $\mathbf{7}$ & $\mathbf{8}$ & $\mathbf{1 0}$ & $\mathbf{9}$ & $\mathbf{9}$ & $\mathbf{9}$ & $\mathbf{1 2}$ & $\mathbf{1 3}$ & $\mathbf{1 2}$ & $\mathbf{1 2}$ \\
Internacional & 7 & 8 & 10 & 9 & 9 & 9 & 12 & 13 & 12 & 12 \\
\hline
\end{tabular}

Nota: Se consideran a las empresas de acuerdo a su concesión, pues existen empresas que tienen más de un servicio.

Fuente: MTC - Dirección General de Transporte Terrestre

Elaboración: MTC - OGPP - Oficina de Estadística

En la tabla $\mathrm{N}^{\circ} 1.3$ tenemos el parque vehicular registrado hasta el año 2016, en estos datos debemos resaltar la cantidad de camiones y remolcadores, que serán nuestra materia de estudio. Ambos suman en el año 2016 un total de 224,766 unidades.

En la tabla $\mathrm{N}^{\circ} 1.4$ tenemos la cantidad de licencias de conducir categoría AIII, correspondientes al mercado potencial que apuntamos con nuestro servicio. Suma un total de 496,900 licencias AIII que son potenciales consumidores de nuestro servicio. 
Tabla $\mathrm{N}^{\circ}$ 1.3: Parque vehicular de empresas de transporte de carga, según ámbito y clase de vehículo, 2007-2016 (en unidades)

\begin{tabular}{|c|c|c|c|c|c|c|c|c|c|c|}
\hline CLABC I & 2007 & 2008 & 2009 & 2010 & 2011 & 2012 & 2013 & 2014 & 2015 & 2016 \\
\hline TOTAL & 98343 & 128047 & 145877 & 148759 & 157517 & 190779 & 216386 & 240230 & 250028 & 287080 \\
\hline AUTOMOVILES & 7 & 7 & 7 & 7 & 7 & 7 & 7 & 7 & 8 & 14 \\
\hline STATION W'AGOR & 10 & 10 & 10 & 9 & 9 & 10 & 10 & 9 & 69 & 128 \\
\hline CMTA. PICK UP & 2839 & 3534 & 4067 & 3946 & 4399 & 5864 & 7499 & 8184 & 8709 & 9317 \\
\hline CMTA. RURABL & 19 & 26 & 27 & 22 & 24 & 25 & 28 & 27 & 31 & 37 \\
\hline CMTA.PANEL & 208 & 273 & 312 & 348 & 481 & 575 & 1029 & 1140 & 1545 & 2538 \\
\hline OMNIBUS & $0 r$ & $0^{7}$ & $0^{r}$ & $0^{r}$ & $0^{5}$ & $0^{7}$ & $0^{r}$ & 12 & 22 & 51 \\
\hline CAMION & 53210 & 68872 & 80068 & 82487 & 87325 & 106151 & 120524 & 139622 & 143198 & 158383 \\
\hline REMOLCADOR & 20082 & 27204 & 29691 & 28878 & 30333 & 35111 & 39717 & 42126 & 44973 & 66145 \\
\hline \multicolumn{11}{|l|}{ REMOLQUEY Y } \\
\hline SEMIREMOLQUE & 21968 & 28121 & 31695 & 33062 & 34939 & 43036 & 47572 & 49100 & 51473 & 50467 \\
\hline N.E. & 0 & 0 & 0 & 0 & 0 & 0 & 0 & 3 & 0 & 0 \\
\hline NACIONAL & 96297 & 124872 & 142662 & 145525 & 153411 & 186872 & 210841 & 234316 & 241697 & 277422 \\
\hline AUTOMOVILES & 7 & 7 & 7 & 7 & 7 & 7 & 7 & 7 & 8 & 14 \\
\hline STATION WAGOR & 10 & 10 & 10 & 9 & 9 & 10 & 10 & 9 & 69 & 128 \\
\hline CMTA. PICK UP & 2839 & 3534 & 4067 & 3946 & 4396 & 5862 & 7495 & 8180 & 8700 & 9301 \\
\hline CMTA. RURRAL & 19 & 26 & 27 & 22 & 24 & 25 & 28 & 27 & 31 & 37 \\
\hline CMTA. PANEL & 208 & 273 & 312 & 348 & 481 & 575 & 1029 & 1140 & 1544 & 2535 \\
\hline OMNIBUS & & & & & & & & 12 & 22 & 51 \\
\hline CAMION & 52992 & 68637 & 79831 & 82336 & 87172 & 106025 & 120217 & 139230 & 142324 & 157106 \\
\hline REMOLCADOR & 19314 & 25945 & 28410 & 27475 & 28497 & 33366 & 37247 & 39634 & 41456 & 62171 \\
\hline \multicolumn{11}{|l|}{ REMOLQUE Y } \\
\hline SEMIREMOLQUE & 20908 & 26440 & 29998 & 31382 & 32825 & 41002 & 44808 & 46074 & 47543 & 46079 \\
\hline N.E. & 0 & 0 & 0 & 0 & 0 & 0 & 0 & 3 & 0 & 0 \\
\hline INTERNACION. & 2046 & 3175 & 3215 & 3234 & 4106 & 3907 & 5545 & 5914 & 8331 & 9658 \\
\hline AUTOMOVILES & 0 & 0 & 0 & 0 & 0 & 0 & 0 & 0 & 0 & 0 \\
\hline STATION WAGON & 0 & 0 & 0 & 0 & 0 & 0 & 0 & 0 & 0 & 0 \\
\hline CMTA. PICK UP & 0 & 0 & 0 & 0 & 3 & 2 & 4 & 4 & 9 & 16 \\
\hline CMTA. RURRAL & 0 & 0 & 0 & 0 & 0 & 0 & 0 & 0 & 0 & 0 \\
\hline CMTA. PANEL & 0 & 0 & 0 & 0 & 0 & 0 & 0 & 0 & 1 & 3 \\
\hline OMNIBUS & 0 & 0 & 0 & 0 & 0 & 0 & 0 & 0 & 0 & 0 \\
\hline CAMION & 218 & 235 & 237 & 151 & 153 & 126 & 307 & 392 & 874 & 1277 \\
\hline REMOLCADOR & 768 & 1259 & 1281 & 1403 & 1836 & 1745 & 2470 & 2492 & 3517 & 3976 \\
\hline \multicolumn{11}{|l|}{ REMOLQUE $Y$} \\
\hline SEMIREMOLQUE & 1060 & 1681 & 1697 & 1680 & 2114 & 2034 & 2764 & 3026 & 3930 & 4388 \\
\hline N.E. & 0 & 0 & 0 & 0 & 0 & 0 & 0 & 0 & 0 & 0 \\
\hline
\end{tabular}

Nota: La información es del Padrón de Transportistas de Carga Nacional, incluye empresas de transporte de carga internacional.

Fuente: MTC - Dirección General de Tranporte Terrestre

Elaboración: MTC - OGPP - Oficina de Estadística 
Tabla $\mathrm{N}^{\circ}$ 1.4: Licencias de conducir a nivel nacional AIII, 2007-2016

\begin{tabular}{|c|c|c|c|c|c|c|c|}
\hline AÑ̃o & TOTAL & Nuevas & Canje & $\begin{array}{c}\text { Revalidació } \\
\mathbf{n}\end{array}$ & Recategorización & $\begin{array}{l}\text { Recarnetizaci } \\
\text { ón A-III }\end{array}$ & Duplicados \\
\hline 2007 & 692369 & 119660 & 6914 & 352334 & 56782 & 80311 & 76368 \\
\hline 2008 & 470506 & 108508 & 1396 & 237386 & 36230 & 0 & 86986 \\
\hline 2009 & 445489 & 100561 & 1411 & 182602 & 21166 & 9419 & 130330 \\
\hline 2010 & 527232 & 111970 & 1574 & 258077 & 22105 & 14146 & 119360 \\
\hline 2011 & 553418 & 148591 & 1760 & 235006 & 52563 & 0 & 115498 \\
\hline 2012 & 543602 & 163774 & 2065 & 194972 & 67007 & 0 & 115784 \\
\hline 2013 & 740869 & 202905 & 2200 & 340859 & 82993 & 0 & 111912 \\
\hline 2014 & 798154 & 248160 & 3661 & 316664 & 99183 & 0 & 130486 \\
\hline 2015 & 742527 & 253384 & 2511 & 289134 & 76816 & 0 & 120682 \\
\hline 2016 & 1003667 & 289838 & 3615 & 496900 & 74512 & 0 & 138802 \\
\hline
\end{tabular}

Estimamos que, en el mercado peruano, la cantidad de conductores que tienen preparación en buen manejo y manejo económico no debe sobrepasar el 5\% de conductores, los cuales pertenecen a empresas que realizan constantemente capacitaciones a su personal; por ello, creemos que es necesaria la propuesta de nuestro negocio.

\subsection{Marco teórico y Mercado (benchmark y mejores prácticas empresariales)}

Carreño, A. (2011), en su libro Logística de la A a la Z indica "El transporte permite el traslado físico de productos entre 2 instalaciones de la cadena de suministros, bajo el medio terrestre (carretero, ferroviario), acuático (marítima, fluvial, lacustre), el medio aéreo y finalmente los ductos" (p.153).

En esta primera definición podemos concluir que el traslado de mercancías, bienes, productos en proceso y/o insumos, se puede realizar por diferentes medios de transporte como el terrestre, marítimo, aéreo, entre otros, desde un origen hasta un destino final.

Según el texto de la Industria del transporte y el almacenamiento de la enciclopedia de la Organización Internacional del Trabajo (1992) indica:

El transporte por carretera mueve personas, animales y mercancías de todo tipo... las personas que viajan por carretera suelen utilizar el autobús... camiones de diversos modelos, entre los que figuran semirremolques, camiones cisterna, volquetes, 
combinaciones de remolques dobles y triples, grúas móviles, camiones de reparto y camionetas. Los pesos brutos de estos vehículos establecidos en la legislación (que dependen de la jurisdicción) oscilan entre 2.000 y más de $80.000 \mathrm{~kg}$. Transportan todo tipo de artículos: paquetes pequeños y grandes, maquinaria, piedras y arena, acero, leña, líquidos inflamables, gases comprimidos, explosivos, materiales radiactivos, sustancias químicas corrosivas y reactivas, líquidos criogénicos, productos alimenticios, alimentos congelados, cereales a granel y ganado ovino y bovino.

Como tenemos en esta definición, el transporte es el traslado de personas, animales o bienes de un lugar a otro. Existe una diversidad de capacidades de carga que van desde las 2 ton hasta las 80 ton. Por otro lado, también indica que, en los bienes a transportar, existe una variedad de tipos como son los minerales, maquinarias, explosivos, carga en general, entre otros.

Asimismo, el texto señala:

Además de conducir el vehículo, los camioneros lo revisan antes de cada viaje, comprueban los documentos de expedición, verifican la correcta colocación de placas y señales y mantienen el libro de ruta. Asimismo, son responsables del mantenimiento y la reparación del vehículo, de la carga y la descarga de la mercancía (a mano o con una carretilla elevadora, una grúa u otro dispositivo) y del cobro del dinero recibido a cambio de los artículos entregados. En caso de accidente, el conductor se ocupa de vigilar la mercancía y solicitar asistencia. Si en el incidente intervienen materiales peligrosos, intentar a veces controlar los derrames, detener las fugas o extinguir un incendio, incluso aunque carezca de la formación adecuada o del equipo necesario.

Podemos concluir que, la función de los conductores no solo es manejar una unidad de carga pesada o de pasajeros, sino también tener la responsabilidad de garantizar la conservación de la unidad, entrega de las mercaderías en la calidad y tiempo en condiciones pactadas. Esto último puede hacer que los conductores tengan otras responsabilidades y muchas veces que no se puedan concentrar en el manejo como se requiere.

Finalmente, este autor señala: 
Los conductores de autobús pueden transportar a unas pocas personas en una pequeña furgoneta o conducir vehículos de mediano o gran tamaño en los que se desplazan cien o más pasajeros. Son responsables de la subida y la bajada del pasaje en condiciones de seguridad, de la información y, en ocasiones, del cobro de billetes y el mantenimiento del orden. Asimismo, estos trabajadores pueden encargarse del mantenimiento y la reparación del vehículo y de la carga y descarga de mercancías y equipajes. Los accidentes de los vehículos a motor constituyen uno de los riesgos más graves con que se enfrentan los conductores de camiones y autobuses. Este riesgo se agrava si el mantenimiento del vehículo no es el adecuado, sobre todo si los neumáticos están desgastados o el sistema de frenos falla. La fatiga provocada por horarios de trabajos prolongados o irregulares o por otros factores de estrés, aumenta la probabilidad de un accidente. Una velocidad excesiva o el transporte de cargas con pesos superiores a lo aconsejable agravan la situación, al igual que el tráfico denso y las condiciones meteorológicas adversas, que disminuyen la tracción y la visibilidad. Si en el accidente intervienen materiales peligrosos, el conductor y los pasajeros quedan expuestos a lesiones aún más graves (por exposición a productos tóxicos, quemaduras, etc.)

Como podemos entender en esta definición, estas actividades adicionales causan fatiga, cansancio y estrés, porque no solo el conductor está involucrado en la actividad propia de conducir, sino que también realiza otras actividades descritas previamente sobre el servicio que brinda. Asimismo, es responsable del mantenimiento, conservación de la unidad, check list de esta, entre otras, que demandan que la concentración no esté solo en la conducción.

Como parte de este trabajo, mostramos algunas estadísticas importantes para entender el impacto que tienen los accidentes en transporte terrestre en nuestro medio y comparadas en el mundo.

En la Figura 1.2 mostramos el número de accidentes, fallecidos y heridos en los años 2011 hasta el año 2014, vemos un comportamiento casi constante en todos estos años, entre los fallecidos podemos apreciar un número que no baja de los 535 por año y entre los heridos en este mismo periodo que no baja de las 3,500 personas involucradas en por lo menos 777 accidentes por año. 
Figura 1.2: Accidentes de tránsito con daños personales de vehículos de servicio de transporte terrestre de personas, carga y mercancías, por número de accidentes, fallecidos y heridos.

\section{Perú - Vías Nacionales: 2010-2014}

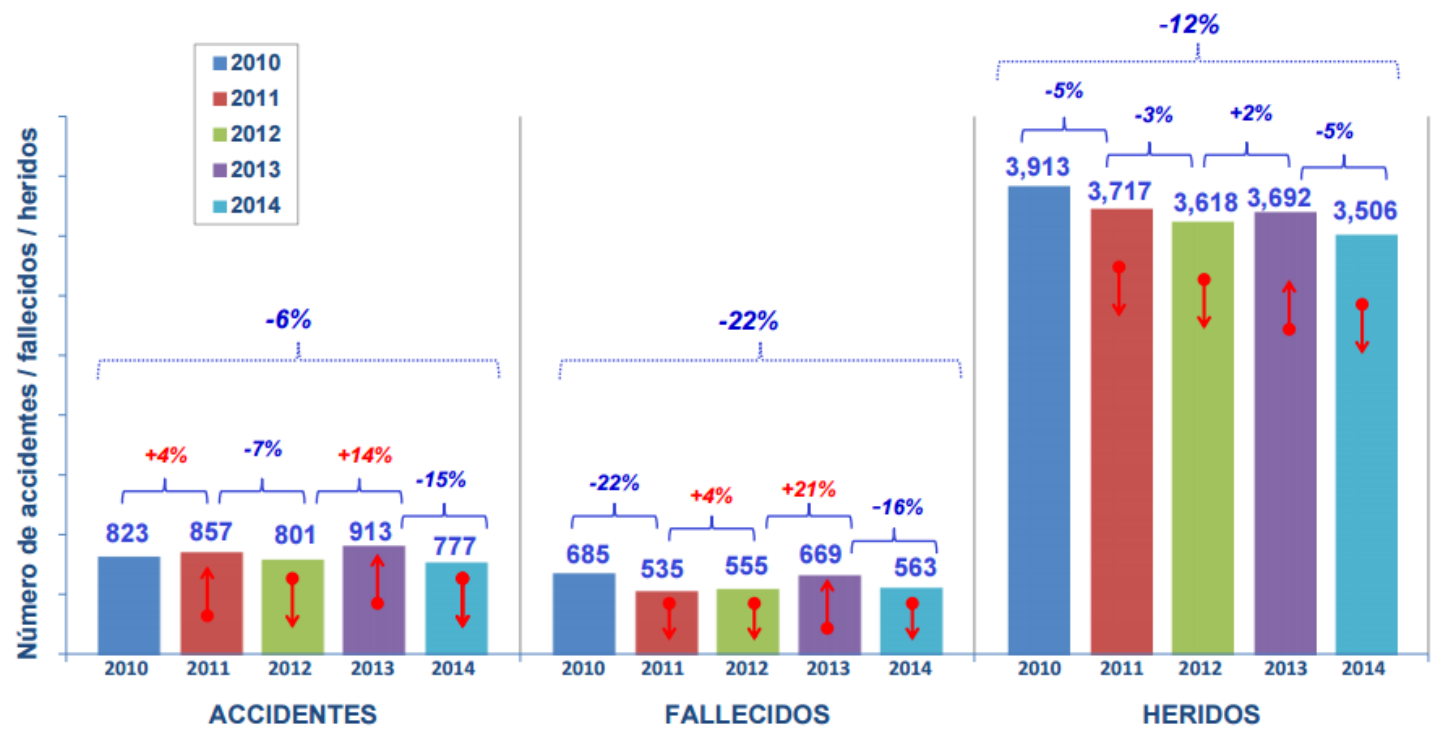

Fuente: DIRPRCAR - PNP, Empresas de Servicio de Transporte, Medios de Comunicación

En la figura 1.3 podemos apreciar la cantidad de accidentes ocurridos en el servicio de transporte terrestre de personas, carga y mercancías. Por tipo de unidad, el camión y/o semitrailer tiene la mayor cantidad de accidentes, con más de 610 por año en el lapso del 2010 al 2014. En segundo lugar, tenemos los accidentes en omnibuses con una cantidad de 320 como mínimo por año en el mismo periodo de tiempo. 
Figura 1.3: Accidentes de tránsito con daños personales de vehículos de servicio de transporte terrestre de personas, carga y mercancías, vehículos participantes según clasificación.

Perú - Vías Nacionales: 2010-2014

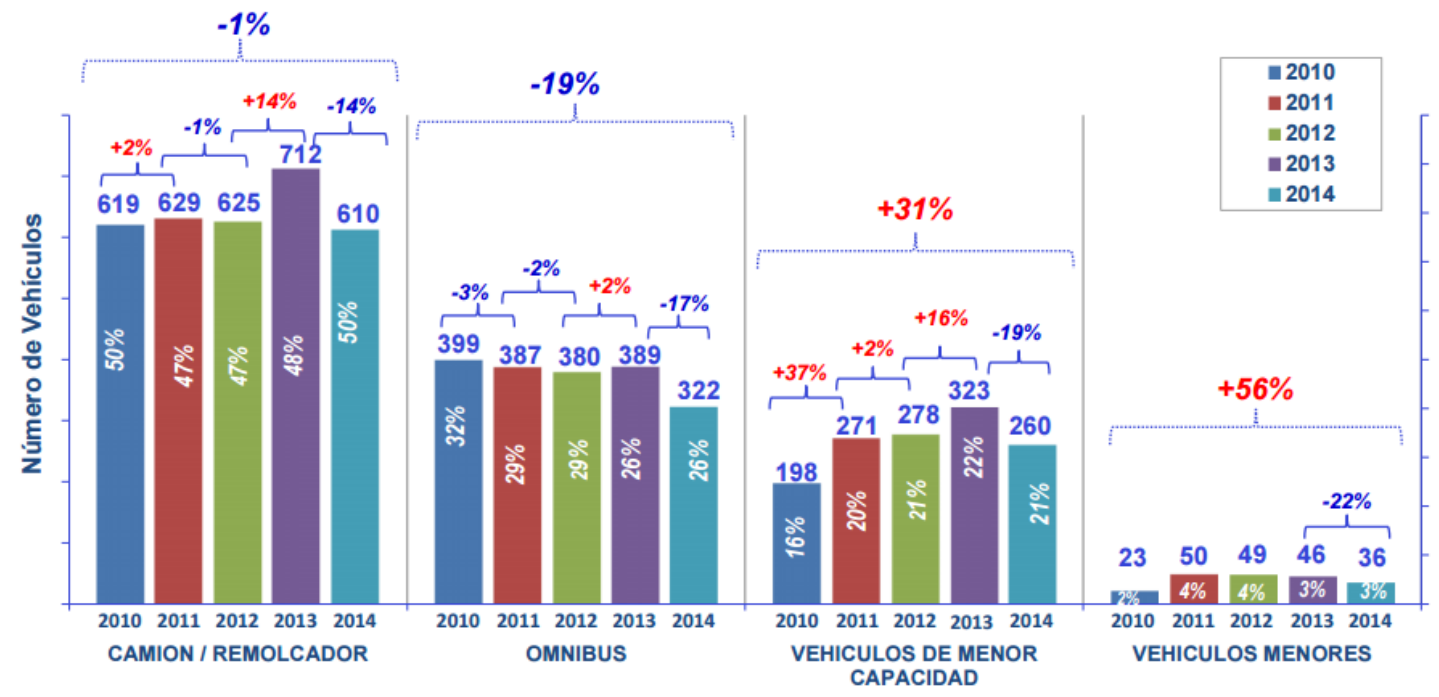

Fuente: DIRPRCAR - PNP, Empresas de Servicio de Transporte, Medios de Comunicación

En la figura $\mathrm{N}^{\circ} 1.4$, podemos apreciar la cantidad de accidentes ocurridos en el transporte terrestre. pero de unidades menores reportado en Vías Nacionales. El número de accidentes es menor, mas no despreciable, ya que igual desencadena en muertes y daños de personas. 
Figura 1.4: Accidentes de tránsito con daños personales de vehículos de servicio de transporte terrestre de personas, carga y mercancías, participación de vehículos de menor capacidad.

\section{Perú - Vías Nacionales: 2010-2014}

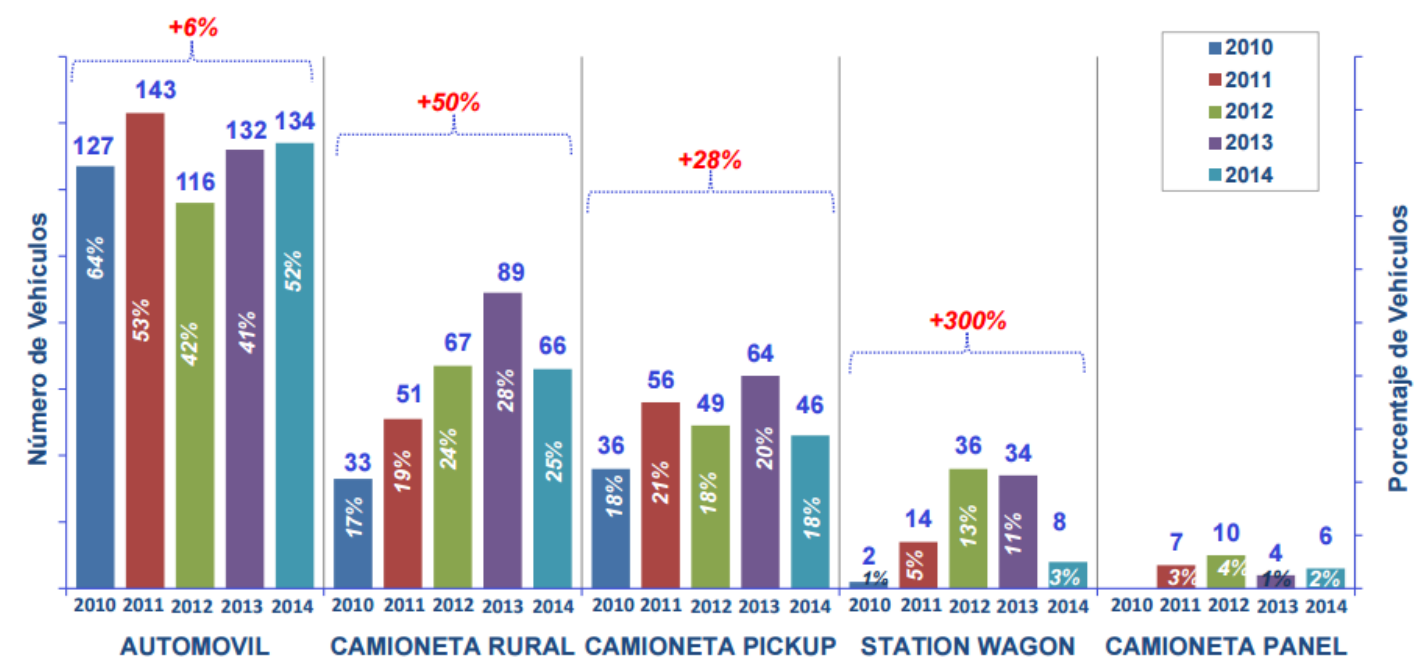

Fuente: DIRPRCAR - PNP, Empresas de Servicio de Transporte, Medios de Comunicación

Finalmente, en la Figura 1.5 sobre los accidentes de tránsito con daños personales de vehículos de servicio de transporte terrestre de personas, carga y mercancías en lapsos de dos horas, vemos un pronunciado número de accidentes en el horario de las 4:00 horas hasta las 8:00 horas, esta gráfica nos ayudará también para instruir a los conductores sobre las horas con mayor número de accidentes. 
Figura 1.5: Accidentes de tránsito con daños personales de vehículos de servicio de transporte terrestre de personas, carga y mercancías, según horario de incidencia (periodos de 2 horas),

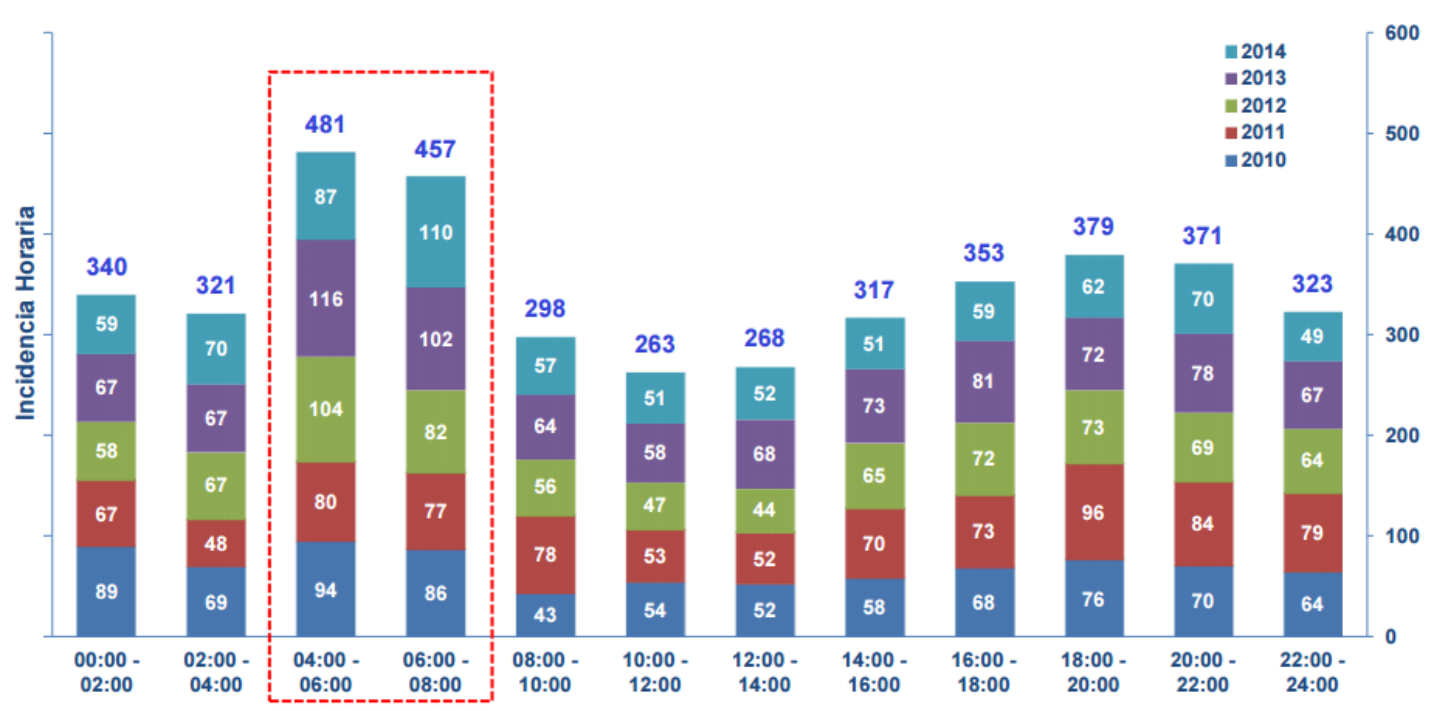

Fuente: DIRPRCAR - PNP, Empresas de Servicio de Transporte, Medios de Comunicación

En la Tabla $\mathrm{N}^{\circ}$ 1.5, mostramos un indicador que muestra la cantidad de Accidentes de tránsito fatales y no fatales por año, según clase: 2007 - 2016. Donde destacan los choques y atropellos. 
Tabla 1.5: Accidentes de tránsito fatales y no fatales por año, según clase: 2007 - 2016

\begin{tabular}{|c|c|c|c|c|c|c|c|c|c|c|}
\hline CLASE & 2007 & 2008 & 2009 & 2010 & 2011 & 2012 & 2013 & 2014 & 2015 & 2016 \\
\hline TOTAL & 79972 & 85337 & 86026 & 83653 & 84495 & 95692 & 102762 & 101307 & 95532 & 89304 \\
\hline \% & 100.0 & 100.0 & 100.0 & 100.0 & 100.0 & 100.0 & 100.0 & 100.0 & 100.0 & 100.0 \\
\hline Atropello & 22778 & 23357 & 22267 & 19673 & 18475 & 19859 & 20676 & 17713 & 15901 & 16423 \\
\hline$\%$ & 28.5 & 27.4 & 25.9 & 23.5 & 21.9 & 20.8 & 20.1 & 17.5 & 16.6 & 18.4 \\
\hline Choque & 45656 & 48592 & 50941 & 51679 & 52200 & 57555 & 64304 & 61906 & 59673 & 55026 \\
\hline$\%$ & 57.1 & 56.9 & 59.2 & 61.8 & 61.8 & 60.1 & 62.6 & 61.1 & 62.5 & 61.6 \\
\hline Volcadura & 2424 & 2623 & 2216 & 1847 & 2076 & 2390 & 2438 & 1788 & 1239 & 2901 \\
\hline$\%$ & 3.0 & 3.1 & 2.6 & 2.2 & 2.5 & 2.5 & 2.4 & 1.8 & 1.3 & 3.2 \\
\hline Caída de Pasajero & 3021 & 3011 & 2636 & 2641 & 2515 & 2707 & 2742 & 2944 & 2503 & 2305 \\
\hline$\%$ & 3.8 & 3.5 & 3.1 & 3.2 & 3.0 & 2.8 & 2.7 & 2.9 & 2.6 & 2.6 \\
\hline Incendio & 459 & 395 & 225 & 180 & 369 & 643 & 324 & 324 & 141 & 103 \\
\hline$\%$ & 0.6 & 0.5 & 0.3 & 0.2 & 0.4 & 0.7 & 0.3 & 0.3 & 0.1 & 0.1 \\
\hline Otros & 5634 & 7359 & 7741 & 7633 & 8860 & 12538 & 12278 & 16632 & 16075 & 12546 \\
\hline$\%$ & 7.0 & 8.6 & 9.0 & 9.1 & 10.5 & 13.1 & 11.9 & 16.4 & 16.8 & 14.0 \\
\hline
\end{tabular}

Cobertura: Nacional

Fuente: Accidentes Declarados en las Unidades de la PNP

Elaboración: EMG-PNP/OFITEL Y MTC/OGPP - Oficina de Estadística

Para entender la magnitud de estas eventualidades, colocamos algunas imágenes que nos ayudarán a entender el tipo de incidentes que pueden ocurrir en carreteras.

En la figura $\mathrm{N}^{\circ} 1.6$, vemos un ómnibus también en un accidente vehicular que tuvo un choque frontal con otro ómnibus que manejaba en sentido contrario, algo muy común en las vías de doble sentido vehicular. 
Figura $\mathrm{N}^{\circ}$ 1.6: Accidente vehicular de un bus de pasajeros

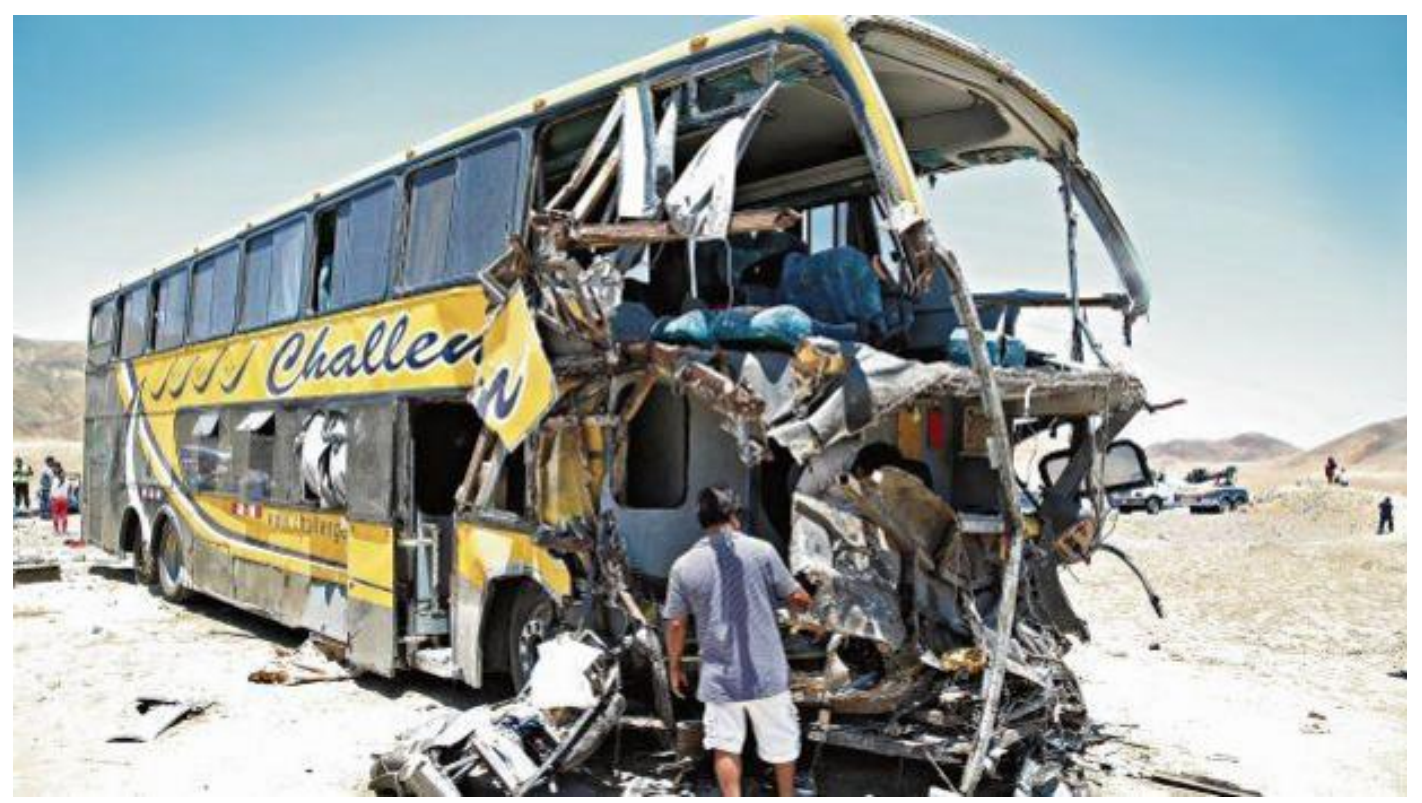

Fuente: El Comercio

\subsection{Motivación del Proyecto}

Si bien el Perú cuenta con organismos como el Ministerio de Transportes y Comunicaciones (MTC) y la Superintendencia de Transporte Terrestre de Personas, Carga y Mercancías (SUTRAN) como entidades de control nacional en el transporte terrestre que regulan tanto el transporte de carga y el de pasajeros, consideramos que estos no son lo suficientemente capaces para abarcar el control, regulación, supervisión y capacitación de todo el transporte terrestre; esto, debido al gran número de accidentes de tránsito ocurridos en el Perú. El número de muertos en el año 2015 es de 489 según SUTRAN.

Por otro lado, ante un entorno tan competitivo como el de transporte terrestre de carga y pasajeros, y ante la necesidad de implementar estrategias en reducción de costos, las compañías buscan diferentes maneras de reducirlos; por lo tanto, capacitar a conductores en un manejo económico se presenta como una alternativa viable, pues se concentrará en reducir el consumo de combustible (costo más elevado en la estructura de costos) y no tener un desgaste prematuro del motor, principalmente. 
Otra motivación, es aplicar los conocimientos aprendidos en la Maestría de Administración de Negocios cursados en la Universidad de Lima con el objetivo de obtener el grado académico de magíster.

De la misma manera, nuestra motivación también es generar conocimiento y poder compartirlo para reducir los accidentes de tránsito, así como crear conciencia social en las empresas de transporte para la reducción de estos siniestros, y aportar no solo desde un punto de vista social, sino también económico. Lo anterior se podrá ver reflejado en beneficios a la comunidad con la reducción de accidentes, muertes y daños medioambientales.

Como una última motivación, tenemos la intención de incrementar la rentabilidad de las empresas de transporte, debido a la mala gestión respecto a seguridad y ámbito económico; por ende, el presente trabajo busca también animar a los empresarios para invertir en estos cursos de capacitación y reforzamiento.

En el desarrollo del proyecto también buscaremos un análisis para identificar los motivos de estos accidentes.

\subsection{Percepción de la necesidad: análisis problema-solución}

Como ya se ha mencionado, tenemos varios problemas latentes, con varias alternativas de solución viables para resolverlos. En la Tabla $\mathrm{N}^{\circ} 1.6$ se puede apreciar, por un lado, todos los problemas que se pueden presentar por lo descrito anteriormente, así como las posibles medidas que estamos planteando. 
Tabla $N^{\circ}$ 1.6: Problemas y soluciones de la necesidad planteada

\begin{tabular}{|c|c|}
\hline Problemas & Soluciones \\
\hline $\begin{array}{l}\text { - Accidentes de tránsito con muerte } \\
\text { de personas } \\
\text { - Accidentes de tránsito con } \\
\text { pérdidas de daños materiales } \\
\text { - Daños medioambientales } \\
\text { - Alto consumo de combustible } \\
\text { - Desgaste prematuro del motor } \\
\text { - Desorden vehicular y congestión }\end{array}$ & $\begin{array}{l}\text { - } \begin{array}{l}\text { Capacitaciones en manejo } \\
\text { defensivo }\end{array} \\
\text { - } \begin{array}{l}\text { Entrenamiento en manejo } \\
\text { económico }\end{array} \\
\text { - } \begin{array}{l}\text { Refuerzo de la reglamentación } \\
\text { vigente de tránsito }\end{array} \\
\text { - } \begin{array}{l}\text { Proceso de selección e inducción } \\
\text { de conductores ingresantes }\end{array}\end{array}$ \\
\hline
\end{tabular}

Elaboración propia

Ante los problemas señalados, se generan diversos escenarios para enfrentarlos, reducirlos o mitigarlos. Una vez iniciado este trabajo de capacitación, incorporaremos indicadores de gestión que nos darán una medida de los avances que podemos tener. Entre los indicadores principales que comenzaremos a medir tenemos: la cantidad de accidentes por millón de kilómetros, las horas de inducción y capacitación por conductor, las evaluaciones a los conductores en ruta, consumos de combustibles por ruta, entre otros.

De esta manera se podrá controlar el avance en la gestión y cumplimiento de estrategias empresariales.

\subsection{Descripción de la idea y la oportunidad}

La idea del negocio parte de los problemas y necesidades ya señalados - como es la falta de capacitación a los conductores y tener personal más preparado- con el objetivo de reducir o eliminar accidentes de tránsito y a la vez incrementar los beneficios económicos de las empresas de transporte.

Ante los requerimientos mencionados, tenemos la idea de crear esta empresa que brindará principalmente capacitación y diferentes servicios para obtener los siguientes beneficios:

- Reducción en los costos por consumo de combustible. 
- Reducción en los costos por mantenimiento.

- Reducción del número de accidentes.

- Fortalecer el proceso de selección e inducción de conductores nuevos

- Establecimiento de itinerarios, hojas de ruta y descansos de conductores.

- Mejorar la imagen de la empresa hacia sus clientes en temas de seguridad y oportunidades en el transporte.

El servicio consistirá en:

- Capacitar in situ al conductor en un manejo económico.

- Establecimiento de indicadores de control, como:

- Consumo de combustible

- Indicadores de control de la unidad, llámese revoluciones del motor por minuto, temperaturas, presiones, entre otros.

- Evaluar y clasificar el conocimiento del manejo de conductores.

- Establecer itinerarios de viaje.

- Establecer lineamientos de rotación y descansos de conductores

- Evaluación de rutas críticas.

- Establecer investigación de accidentes con el fin de obtener mejores prácticas en seguridad.

Este servicio es innovador en el mercado porque no existen empresas que se dediquen exclusivamente a lo explicado, solo existen empresas que se dedican a una o dos actividades descritas, pero no la gestionan de manera integrada.

\subsection{Justificación del atractivo de la propuesta}

La justificación de la implementación de una empresa capacitadora en manejo defensivo en transporte de carga y pasajeros, se da por la alta tasa de accidentes en carreteras y por la falta de empresas que brinden este tipo de servicios de inducción y capacitación. Así también, por la necesidad de que existan conductores capacitados y empresas que cumplan con los requisitos mínimos de control en la gestión de su flota.

Los objetivos que nos planteamos desarrollar como empresa son los siguientes:

- Reducir accidentes de tránsito.

- Reducir el consumo de combustible.

- Conocer los parámetros de manejo. 
- Establecer un orden vehicular por parte de las empresas de transporte de carga y pasajeros.

- Evaluar rutas críticas en el transporte.

- Estandarizar mediante hojas de ruta los tiempos y velocidades en el manejo.

\subsection{Estrategia inicial y objetivos de alcance}

La empresa que vamos a implementar tendrá dos objetivos estratégicos: el primero consistirá en capacitar a conductores en manejo defensivo in situ, conocimiento de la unidad de transportes y reconocimiento de los parámetros de control de la unidad. Mientras que el segundo, será beneficiar a la empresa de transportes con reducción de costos en combustible por un manejo económico, establecimiento de parámetros de control del transporte, establecimiento de hojas de ruta, no tener un desgaste prematuro del motor, y fortalecimiento de los procesos de selección e inducción de conductores ingresantes. Todo ello conllevará a elevar la competitividad en el mercado, pues tendrá como estrategia, ser un producto diferenciado y una reducción en sus costos de operación.

Los objetivos que buscamos en el presente proyecto son:

- Reducir el número de accidentes en transporte terrestre de carga y de pasajeros.

- Reducir los costos por consumo de combustible.

- Reducir los costos por mantenimiento.

- Reducir los costos por accidentes.

- Fortalecer el proceso de selección e inducción de conductores nuevos.

- Establecer itinerarios, hojas de ruta y descansos de conductores.

- Implementar un programa de rotación de conductores.

- Mejorar la imagen de la empresa hacia sus clientes en temas de seguridad y oportunidades en el transporte.

\subsection{Impacto comercial y responsabilidad social}

Desde el punto de vista social, considero que se logrará aportar mucho para obtener beneficios, ya que la implementación de este tipo de proyectos ayudará a reducir el número de fallecidos en accidentes de tránsito en el transporte de carga y pasajeros. Así 
también, buscamos lograr impactar en la sociedad, pues el número de fallecidos solo en el año 2015 asciende a 489 víctimas, cifra importante de familias que se han visto afectadas negativamente por estos accidentes.

Como apoyo social, evaluamos la posibilidad de brindar capacitaciones a empresas que no pueden acceder económicamente a estos servicios de seguridad vial, pero que estén involucrados directamente, como los mototaxis.

Por otro lado, también buscamos un impacto ambiental favorable, debido a que algunos tipos de transporte son los mayores causantes de daños medioambientales como el transporte de combustibles o químicos, que ante un derrame podrían contaminar ríos, lagunas u otros.

Desde el punto de vista comercial, las empresas que nos contraten se verán beneficiadas en lo que respecta a:

- Reducción de costos por menos consumo de combustible y mantenimiento.

- Su capacidad instalada no decaerá por la reducción de accidentes y por ende, reducirán sus unidades siniestradas.

- Incremento en las ventas por tener actividades que conlleven a un transporte seguro y por el respaldo de presentar un reducido número de accidentes. 


\section{CAPÍTULO II: IDEA, INVESTIGACIÓN Y VALIDACIÓN DE SOLUCIÓN}

La idea de la presente tesis es implementar una empresa capacitadora en manejo seguro que, como ya mencionamos, instruya a los conductores de unidades de carga y de pasajeros en un manejo defensivo y económico; para ello, se llevará a cabo una investigación de mercado que permita validar las necesidades que existan y el modelo de negocios que se quiere implementar.

\subsection{Diseño y metodología de la investigación}

La hipótesis que utilizaremos es una hipótesis descriptiva, ya que es posible demostrar cómo la capacitación reduce el número de accidentes y los costos de operación en el transporte terrestre de carga y pasajeros.

\subsection{Validación de hipótesis}

Hipótesis (H1): La capacitación in situ a conductores de transporte de carga y de pasajeros está positivamente relacionada a la reducción del número de accidentes de tránsito y en su reducción de costos operativos.

Hipótesis nula (H0): La capacitación in situ a conductores de transporte de carga y de pasajeros no está positivamente relacionada a la reducción del número de accidentes de tránsito y en su reducción de costos operativos.

\subsection{Validación de la solución}

La validación de la propuesta será presentada mediante entrevistas realizadas al personal involucrado en el transporte terrestre, como los gerentes generales, gerentes de transporte, gerentes de operaciones, jefes de transporte y administradores de conductores.

Tomaremos una muestra estadística sobre la cantidad de entrevistas y luego presentaremos los resultados para tener claridad en la viabilidad de nuestra oferta. 
También podremos conocer cuántas empresas quisieran contratar servicios similares, o servicios parciales, entre otros resultados.

\subsection{Muestreo Poblacional}

Nuestra población a considerar serán todas las empresas de transporte de carga y de pasajeros a nivel nacional. Según la Tabla $\mathrm{N}^{\circ} 2.1$, tenemos 7,251 unidades de transporte de pasajeros, según la tabla $\mathrm{N}^{\circ} 3$ tenemos 37,247 remolcadores y 120,217 camiones y con un universo de 359,873 licencias de conducir tipo AIII que son potenciales consumidores de nuestro servicio.

Tabla $\mathrm{N}^{\circ}$ 2.1: Cantidad de unidades de carga pasajeros y licencias de conducir

\begin{tabular}{|l|r|}
\hline \multicolumn{1}{|c|}{ Tipo } & Cantidad \\
\hline Unidades de transporte de pasajeros & 10,183 \\
\hline Unidades de transporte de carga & 66,145 \\
\hline Licencias de conducir tipo AIII & 496,900 \\
\hline
\end{tabular}

Fuente: Elaboración propia

En el trabajo también definiremos la parte de esta población en la que se enfocarán nuestros recursos de publicidad y plantearemos tener entrevistas con personal que esté en este nicho de transporte, con el objetivo de informar nuestra idea de negocio. De esta manera, mejoraremos y/o ajustaremos el servicio a través de una batería de temas secuenciales con respecto al transporte, la seguridad y los costos de operación.

Como comentamos, el perfil de las personas que serán nuestro contacto inicial, está conformado por propietarios, gerentes generales, gerentes de transportes y/o responsables de la administración de conductores o seguridad, de empresas de transporte tanto de pasajeros como de carga. Cabe señalar que estas entrevistas serán realizadas de manera individual en las instalaciones de los entrevistados o en campo. Según la data del Ministerio de Transportes y Comunicaciones al 2016, a nivel nacional existían 106,077 empresas autorizadas para realizar servicios de carga. La data de la misma fuente, para las empresas de transporte de pasajeros en el ámbito nacional, sólo se 
obtuvo hasta el año 2015 en el cual se registraron 446 empresas. Estos dos datos se muestran en las tablas 2.2 y 2.3 .

Tabla 2.2: Empresas autorizadas: Transporte de carga

\begin{tabular}{|c|c|c|c|c|c|c|c|c|c|c|}
\hline \multicolumn{11}{|c|}{ (Número de empresas) } \\
\hline DEPARTAMENTO & 2007 & 2008 & 2009 & 2010 & 2011 & 2012 & 2013 & 2014 & 2015 & 2016 \\
\hline TOTAL & 33382 & 42483 & 50266 & 56504 & 63869 & 71974 & 81115 & 89985 & 95469 & 106077 \\
\hline Amazonas & 127 & 165 & 217 & 240 & 260 & 274 & 292 & 296 & 297 & 349 \\
\hline Ancash & 91 & 290 & 383 & 461 & 584 & 673 & 730 & 807 & 844 & 898 \\
\hline Apurímac & 157 & 289 & 468 & 556 & 583 & 622 & 677 & 794 & 861 & 943 \\
\hline Arequipa & 2914 & 3866 & 4679 & 5372 & 5872 & 6698 & 7466 & 8188 & 8574 & 9430 \\
\hline Ayacucho & 586 & 702 & 784 & 810 & 855 & 892 & 958 & 1116 & 1214 & 1337 \\
\hline Cajamarca & 600 & 761 & 932 & 1099 & 1271 & 1589 & 1774 & 1947 & 2122 & 2348 \\
\hline Callao & 0 & 0 & 0 & 0 & 0 & 781 & - & - & - & \\
\hline Cusco & 1174 & 1375 & 1585 & 1754 & 2009 & 2353 & 2874 & 3472 & 4062 & 4434 \\
\hline Huancavelica & 0 & 0 & 0 & 0 & 0 & 12 & 3 & 9 & 10 & 18 \\
\hline Huánuco & 269 & 426 & 548 & 712 & 842 & 966 & 1091 & 1243 & 1395 & 1588 \\
\hline Ica & 1009 & 1228 & 1388 & 1464 & 1703 & 1896 & 2093 & 2257 & 2313 & 2426 \\
\hline Junín & 2007 & 2531 & 2933 & 3242 & 3414 & 3622 & 3755 & 3912 & 3974 & 4186 \\
\hline La Libertad & 3268 & 4018 & 4539 & 4936 & 5373 & 5871 & 6099 & 6296 & 6244 & 6869 \\
\hline Lambayeque & 1757 & 2309 & 2869 & 3142 & 3528 & 3954 & 4345 & 4624 & 4820 & 5120 \\
\hline Lima & 15076 & 18821 & 22173 & 25199 & 29200 & 32369 & 38610 & 43532 & 46486 & 52765 \\
\hline Loreto & 0 & 0 & 0 & 0 & 0 & 32 & 7 & 7 & 6 & \\
\hline Madre de Dios & 264 & 437 & 591 & 639 & 664 & 682 & 730 & 801 & 799 & 821 \\
\hline Moquegua & 185 & 199 & 227 & 254 & 275 & 307 & 352 & 408 & 436 & 481 \\
\hline Pasco & 34 & 79 & 128 & 160 & 198 & 218 & 232 & 241 & 238 & 244 \\
\hline Piura & 1555 & 2027 & 2345 & 2671 & 3043 & 3440 & 3745 & 4080 & 4286 & 4673 \\
\hline Puno & 595 & 737 & 875 & 987 & 1110 & 1293 & 1538 & 1886 & 2232 & 2569 \\
\hline San Martín & 360 & 491 & 599 & 649 & 707 & 788 & 853 & 981 & 1,086 & 1,175 \\
\hline Tacna & 704 & 914 & 1065 & 1158 & 1281 & 1451 & 1627 & 1742 & 1775 & 1924 \\
\hline Tumbes & 352 & 444 & 516 & 570 & 639 & 679 & 713 & 725 & 728 & 755 \\
\hline Ucayali & 298 & 374 & 422 & 429 & 458 & 512 & 551 & 621 & 667 & 718 \\
\hline
\end{tabular}

Nota: La Región Callao, esta incluida en la Región Lima; la información es del Padrón de Transportistas

de Carga Nacional, conformado por Personas Jurídicas y Personas Naturales.

Fuente: MTC - Dirección General de Transporte Terrestre

Elaboración: MTC - OGPP - Oficina de Estadística

Tabla 2.3: Empresas autorizadas: Transporte de pasajeros

\begin{tabular}{|r|l|l|l|l|l|l|}
\hline Año & \multicolumn{1}{|c|}{$\mathbf{2 0 1 0}$} & $\mathbf{2 0 1 1}$ & $\mathbf{2 0 1 2}$ & $\mathbf{2 0 1 3}$ & $\mathbf{2 0 1 4}$ & $\mathbf{2 0 1 5}$ \\
\hline Empresas autorizadas & 358 & 354 & 370 & 396 & 438 & 446 \\
\hline
\end{tabular}

Fuente: GTT-OGPP /Dirección de regulación y normatividad - MTTC

Elaboración: Propia

Nuestro mercado objetivo o clientes potenciales son las empresas que tienen como propiedad más de 10 unidades, hacemos la salvedad que son empresas que tienen la propiedad a nombre de la empresa. Según los datos, a nivel nacional las empresas de 
carga y de transporte terrestre serían más de 120,000 según la proyección trabajada. Dado que nuestro objetivo es llegar al $0.5 \%$, es decir, algo más de 600 empresas, se estableció una muestra del 5\% de dicha población, para generar la investigación de campo, establecer las principales necesidades y desarrollar las estrategias. De las 30 entrevistas pactadas, sólo se lograron realizar 22 debido a cambios de último minuto de algunos entrevistados.

El método elegido fue entrevistas, las cuales se llevaron a cabo con dueños, gerentes y/o responsables de la administración de empresas de transporte terrestre de personas o de carga. En las entrevistas se encontraron problemas comunes, los que listamos a continuación.

- Accidentes de tránsito por exceso de confianza del conductor.

- Multas impuestas, sobre todo por desconocer las principales normas de tránsito. Esto causa una alta rotación de conductores calificados, con los costos de desvinculación que acarrea.

- Costos excesivos en combustible, por un alto consumo, sobre todo en rutas a provincias.

- Mal trato de conductores en el transporte de pasajeros.

- Inclusión de paraderos informales, en el transporte de pasajeros, generando inseguridad y costos en combustible adicional.

- Desgaste prematuro de las unidades por el desconocimiento de los parámetros de manejo.

En lo referente al interés sobre contar con servicios de una empresa como la nuestra de los 22 entrevistados, 6 señalaron que no requerían un servicio como este y 21 señalaron que sí podrían estar interesados. Los resultados se muestran en el Anexo III.

\subsection{Análisis de tendencias y patrones}

Las tendencias encontradas son el incremento de accidentes vehiculares año tras año según los gráficos mostrados. Se encontró una tendencia incremental año tras año, y, como también lo hemos mencionado, el Estado hace muy poco para remediarla. Mientras tanto, la experiencia en otros países que invierten en seguridad vial presenta un patrón de reducción ante estos incidentes. 
El objetivo del presente proyecto es implementar un modelo de negocio que no solo permitirá desarrollar una empresa rentable y viable, sino que también aportará a la comunidad de manera favorable.

\subsection{CANVAS del modelo de negocio}

En la tabla $\mathrm{N}^{\circ} 2.4$ podemos apreciar el Canvas desarrollado para la propuesta del negocio donde incluimos todos los factores analizados. 
Tabla $N^{\circ}$ 2.4: Canvas del modelo de negocio

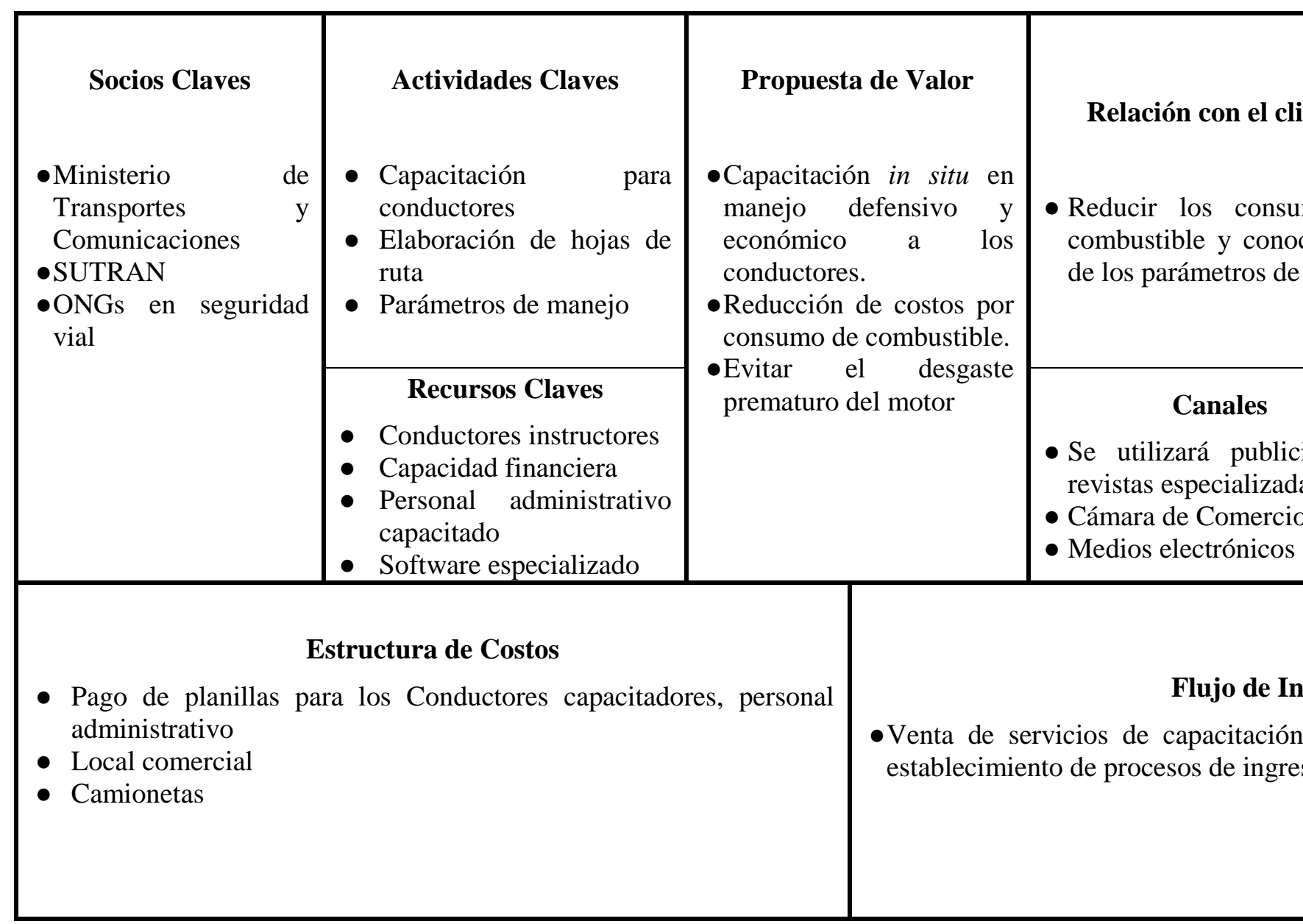

Elaboración propia 


\subsection{Conclusiones parciales}

Las conclusiones a las que podemos llegar luego de haber desarrollado los capítulos uno y dos, son las siguientes:

- Podemos definir que este proyecto consiste en un servicio necesario e innovador, no solo para las empresas de transporte y conductores, sino también a la sociedad.

- El negocio a implementar deberá considerar la inclusión de otros servicios en un futuro.

- Los organismos de estado que regulan, supervisan y controlan el transporte terrestre no son los adecuados, ya que somos uno de los países con más accidentes de tránsito.

- Toda la información por analizar será tomada de bases de datos del INEI, MTC y SUTRAN y entrevistas a propietarios y/o gerentes de transporte terrestre sólidas y líderes en el mercado principalmente.

- Las empresas clientes están interesadas en un servicio como este, debido a los costos que representa no sólo el pago de multas, sino también el de ubicar conductores capacitados y los costos de mantenimiento de las unidades por problemas de conducción.

- Si bien las empresas desarrollan rutas, muchas veces estas no son óptimas o se usan rutas comunes, en donde no se toman en cuenta factores que podrían estar desgastando la unidad y generando molestias en los conductores. 


\section{CAPÍTULO III: PLANEAMIENTO ESTRATÉGICO}

\subsection{Visión}

Ser la empresa líder en el mercado en cuanto a capacitación para la seguridad vial en el transporte de carga y de pasajeros, y convertirnos en expertos en la certificación de manejo económico y seguro.

\subsection{Misión}

Brindar servicios de capacitación a conductores de transporte terrestre de carga y de pasajeros en un manejo económico y seguro, utilizando personal altamente calificado, asegurando la rentabilidad y crecimiento para la organización.

\subsection{Valores y ética}

Los valores que buscará este proyecto como organización son: el respeto, que debemos practicarlo en nuestras labores diarias y transmitirlo en todas las capacitaciones, porque es fundamental para el manejo seguro, así como el respeto por los parámetros de conducción son esenciales en esta labor. La responsabilidad, que debemos inculcar mucho en los participantes conductores, ya que conducir un ómnibus transportando 45 personas, supone una tremenda responsabilidad. Consideraremos también como valores esenciales, la orientación social, la honestidad y la imagen, que además son características de nuestro personal que servirán para fomentar la inclusión en nuestros clientes.

Finalmente, y no menos importante, en toda la organización nos desenvolveremos en un ambiente ético, de respeto por las normas y por la sociedad, para lo cual organizaremos capacitaciones internas que fortalezcan nuestra ética y nuestros valores. 


\subsection{Cultura organizacional}

Nuestra cultura organizacional se desarrollará con los valores descritos en el punto anterior, desde la gerencia general hacia todos los sectores de la empresa. Promulgamos valores arraigados que trabajaremos constantemente - la responsabilidad, el respeto, la orientación al bien social y la honestidad-, todos ellos apoyados o basados en la ética, lo cual dará fuerza a nuestra cultura. Del mismo modo, trabajaremos para que el personal lo sienta y lo viva de esta manera, no solo dentro de la organización sino fuera de ella.

Queremos que nuestros clientes perciban nuestra cultura como una de las principales características o fortalezas de la empresa, para que quieran apostar por ella.

\subsection{Objetivos Estratégicos}

Nuestros objetivos estratégicos han sido clasificados en 2 partes: objetivos primarios y objetivos secundarios.

Objetivos primarios:

- Reducir accidentes en el transporte terrestre de carga y de pasajeros

- Conducir las unidades de transporte bajo parámetros correctos de manejo.

Objetivos secundarios:

- Reducir el consumo de combustible mediante una buena conducción.

- Establecer hojas de rutas y/o itinerarios de los viajes.

- Asesorar a las empresas de transporte en la adecuada gestión de sus operaciones.

- Inculcar valores de respeto, responsabilidad y lealtad a los conductores.

3.6 Análisis externo: Político, legal, circunstancial, económico, geográfico, social, demográfico, cultural, tecnológico, ambiental (PESTEL)

Podemos mencionar, como indica D’Alessio lo siguiente:

Para poder tomar decisiones estratégicas dentro de una organización es necesario conocer el entorno donde se desarrolla. El análisis PESTEL permite considerar los factores del entorno de una manera ordenada y 
estructurada. Al realizar este tipo de análisis, las organizaciones contemplan factores políticos, económicos, sociales, tecnológicos y ecológicos; a partir de los cuales podrán elaborar estrategias para poder adaptarse a las nuevas tendencias que afectan a la industria donde se desenvuelven.

Según el autor, esta herramienta de planificación estratégica que desarrollaremos nos ayudará a identificar el contexto y el entorno en el que se moverá la empresa. Las variables políticas, económicas, socioculturales, tecnológicas, ecológicas y legales son aquellas por las cuales nuestro proyecto empresarial se guiará para decidir las acciones estratégicas que se utilizarán para el mejor futuro en la organización. A continuación, explicamos cada una de ellas:

En el ámbito político, sabemos que en los últimos 30 años no hemos tenido cambios drásticos y seguimos un movimiento democrático, estos últimos gobiernos han demostrado respeto a las leyes y así también lo demuestra nuestro actual presidente Martín Vizcarra; por ende, no deberían cambiar las reglas de juego en lo político, en lo fiscal, ni con los convenios internacionales.

En el aspecto económico, evaluamos que el mercado se encuentra en una etapa de expansión; así lo indican los últimos cuadros del INEI, donde el crecimiento es constante durante los últimos 15 años.

En el aspecto sociocultural, podemos entender que la sociedad está dirigiendo sus actividades a la seguridad, a la protección. Este proyecto apunta hacia eso, por ello, considero que este aspecto es el que mejor nos acompaña, ya que si hacemos las siguientes preguntas: ¿queremos más accidentes?, ¿los conductores deberían tener mayor y mejor capacitación?, ¿les gustaría trabajar mejor con los conductores de omnibuses y camiones de carga en la prevención de accidentes?, todas las respuestas nos acompañarán con los objetivos de la empresa.

Los factores tecnológicos también serán consideramos dentro de nuestro entorno, ya que, si bien la capacitación será in situ, proponemos desarrollar apps que contengan toda la información que requiere el conductor en cada viaje. En ellas, se podrá encontrar la hoja de ruta en donde se indicarán los parámetros, horas de conducción, descanso, entre otros. El ambiente tecnológico actual acompaña a las ideas que desea el proyecto. 
En el sector ecológico, evaluamos el impacto que tendrá nuestro proyecto; por ende, la buena conservación de la unidad conlleva a una menor contaminación del motor al medioambiente.

Los factores legales implican un análisis constante, pues la normativa del Ministerio de Transportes y Comunicaciones es cambiante, tiende a incluir mejoras en el sistema, modificaciones en la normativa y nuevas restricciones en la condiciones de manejo en el transporte de pasajeros como el de carga.

En la tabla $\mathrm{N}^{\circ} 3.1$ visualizamos el impacto que tendrá cada una de las variables en este análisis Pestel, donde validamos que tendrá un análisis positivo en la mayor cantidad de ellas.

3.7 Análisis interno: Competidores potenciales, clientes, proveedores, productos sustitutos, barreras de entrada (PORTER)

El análisis de Michael Porter (1979), determina que existen cinco fuerzas que condicionan la rentabilidad a largo plazo del mercado. La idea que él plantea, es que la organización debe evaluar sus objetivos y recursos frente a ellas, pues rigen la competencia. A continuación, desarrollamos estas cinco fuerzas competitivas. 
Tabla N³.1: Análisis Pestel

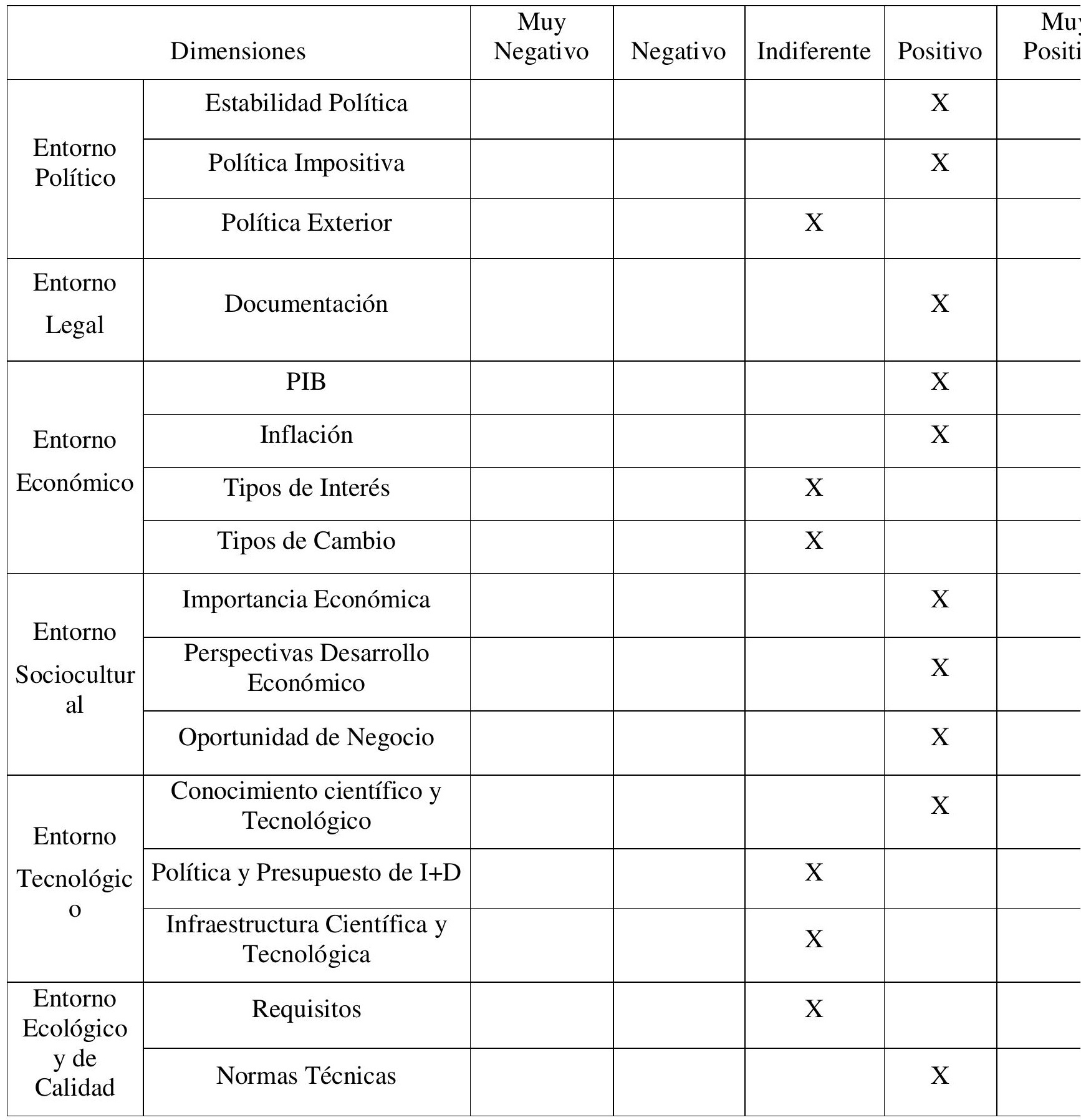

Elaboración propia 


\subsubsection{Poder de negociación de los proveedores}

En este caso, los principales proveedores serían los conductores que se contraten como capacitadores en el servicio. Ellos pueden ejercer un poder significativo, dado que cuentan con la experiencia requerida; sin ellos no se podría brindar el servicio.

\subsubsection{Competidores potenciales}

Las barreras de ingreso al sector son pocas. Desde el punto de vista de la inversión, sin embargo, estas crecen, si se toma en cuenta que se requiere experiencia y conocimiento en el sector para ofrecer un servicio como el señalado.

\subsubsection{Poder de negociación de los clientes}

El poder de negociación de los clientes es fuerte, dado que ellos buscan optimizar su inversión y contar con el mejor servicio. Por este lado, la presión hacia un servicio a bajo costo será el mayor poder que busquen ejercer.

\subsubsection{Sustitutos}

Como sustitutos podemos señalar que existen empresas de conductores que, a nivel de preparación en reglas de manejo y seguridad vial, podrían ser competencia de nuestro servicio. Sin embargo este servicio se brinda en sus oficinas, del mismo modo como parte del servicio al cliente.

\subsubsection{Rivalidad competencia}

En el sector de la asesoría y capacitación de empresas de transporte no se brinda, actualmente, un servicio como el que buscamos desarrollar. Esto hace que nuestra empresa sea única en el rubro. Sin embargo, el modelo es fácilmente replicable, por lo que es vital el que se puedan concretar contratos y relaciones de largo plazo con los clientes. Es por ello que la investigación y conocimiento de los clientes potenciales será vital en los planes comerciales. 


\subsection{Análisis sectorial e Identificación de riesgos y amenazas. Análisis FODA}

Los factores internos y externos evaluados que pueden poner en riesgo y amenazar o afectar el desarrollo normal de la organización son los siguientes:

Fortalezas

- Experiencia del personal técnico.

- Producto flexible, ya que nos podremos amoldar a lo requerido por el cliente, ya sea en tipos de unidades, horarios de trabajo, modalidad de uno o dos conductores, entre otras características.

- El retorno de la inversión por parte del cliente se puede ver reflejado desde el primer día de iniciada la operación, ya que desde ese momento tendremos mejoras en ahorro de combustible e incremento paulatino del manejo seguro.

- Bajos costos operativos iniciales de la organización, ya que no se requerirá mayor inversión en la primera etapa del proyecto.

- Gran variedad de servicios para ofertar.

Debilidades

- Empresa joven con muy poco tiempo de vida como empresa.

- Pocas ventas y pocos clientes podrían inicialmente darnos fragilidad en la continuidad del negocio.

- Poco poder de negociación por la juventud de la empresa y su tamaño.

- Limitada solvencia económica.

- Poco oferta laboral de los conductores capacitadores.

Oportunidades

- Única empresa con este tipo de servicio en el Perú.

- Gran oferta por el servicio en el mercado nacional.

- Explotar un nuevo nicho de mercado.

- La cobertura del servicio se podrá dar por las distintas regiones del país, así como internacionalmente (previa revisión de la normativa del país contratante del servicio).

- Adaptar los servicios a nuevos requerimientos. 


\section{Amenazas}

- Contratación de nuestro personal técnico por parte de los clientes.

- Poco personal técnico calificado en el mercado.

- Empresas de seguridad vial u otras del rubro empiecen a dar un servicio similar.

\subsection{Estrategia de éxito (FODA cruzado)}

Ahora con estas características podemos cruzarlas para encontrar las mejores estrategias que nos lleven a minimizar algunos riesgos o maximizar nuestras oportunidades como lo vemos en la Tabla 3.2 .

Tabla 3.2: Estrategias del FODA cruzado

\begin{tabular}{|c|c|c|}
\hline gias FC & & gias DO \\
\hline & $\begin{array}{l}\text { Como única empresa en el medio con este } \\
\text { servicio, nos podemos introducir en el } \\
\text { mercado de una manera sólida e } \\
\text { innovadora. } \\
\text { La experticia del personal capacitador será } \\
\text { otro pilar para explotar este nuevo } \\
\text { mercado. }\end{array}$ & $\begin{array}{l}\text { - Si bien existen pocos clientes, al tener } \\
\text { gran variedad de servicios se pueden } \\
\text { vender varios productos al mismo } \\
\text { cliente. } \\
\text { - El poco poder de negociación se podrá } \\
\text { paliar mediante la variedad de servicios } \\
\text { que se ofrecerá. }\end{array}$ \\
\hline $\operatorname{gias} \mathrm{F} A$ & & gias DA \\
\hline & $\begin{array}{l}\text { La rápida rentabilidad de lo invertido por el } \\
\text { cliente puede, de cierta manera, generar } \\
\text { lealtad a nuestros clientes. } \\
\text { Si bien contaremos con personal técnico } \\
\text { calificado, debemos revisar la amenaza de } \\
\text { que renuncien, por ello haremos un plan de } \\
\text { contingencia para mitigar este escenario. }\end{array}$ & $\begin{array}{l}\text { - Debemos atenuar el hecho ser una } \\
\text { empresa joven, más el retiro del personal } \\
\text { técnico, mediante el desarrollo del } \\
\text { compromiso del trabajador hacia la } \\
\text { empresa. }\end{array}$ \\
\hline
\end{tabular}




\section{CAPÍTULO IV: Plan de marketing}

\subsection{Planteamiento de objetivos generales de marketing}

Lograr en el primer año captar el $0.05 \%$ de las empresas que conforman nuestro público primario. Con este porcentaje aseguramos la rentabilidad de la empresa como se analizará más adelante en las evaluaciones económica-financieras.

\subsection{Estrategias de marketing:}

\subsubsection{Segmentación y Perfil del cliente}

Nuestro servicio se dirige a las empresas que requieren rentabilizar sus costos de servicio de transporte, a través de la gestión adecuada de los componentes de su servicio: conductores capacitados en rutas y en vehículos, gestión de rutas idóneas, mejora de movimiento de carga, entre otros. Esto repercutirá en que provean un servicio basado en una buena performance, mejorando sus indicadores no solo financieros sino también de imagen y confiabilidad de sus servicios. Nuestros clientes son empresas especializadas dirigidas, a su vez, por expertos transportistas. En este tipo de empresas podemos encontrar dos tipos de perfiles directivos: con formación profesional y sin formación profesional, estos últimos formados en la experiencia. Del mismo modo, es importante conocer cómo es la gestión de la organización, ya que, en empresas familiares, las decisiones pueden tomarse de forma distinta a empresas no familiares. Es por ello que resulta vital conocer muy bien sus necesidades y el perfil del tipo de decisor. El perfil que hemos definido como decisor de nuestro servicio es de la siguiente manera: "Experto en transporte, operaciones y/o logística".

Sus necesidades son distintas según el tipo de empresa:

- Empresa de transporte de carga: su principal necesidad es garantizar que los costos de sus operaciones permitan un margen de ganancia adecuado, además de garantizar la seguridad de la carga que transporta. 
- Empresa de transporte de pasajeros: requieren un servicio que garantice la seguridad e integridad de sus pasajeros, así como un margen que los mantengan competitivos en el mercado.

\subsubsection{Posicionamiento y ventaja competitiva}

Nuestra empresa está formada por expertos con el conocimiento y experiencia en la gestión de empresas de transporte, por lo que conocemos su realidad, los problemas que las empresas atraviesan y su necesidades. Nuestra ventaja radica en que conocemos a profundidad sus requerimientos, por lo que podemos ofrecer un servicio customizado y especializados a las mismas.

Nuestra declaración de posicionamiento es: Para empresas de transporte de carga y pasajeros, nuestra organización tendrá como objetivo la capacitación en manejo eficiente en las variables que afectan el servicio de transporte que ofrece un servicio diferenciado, ya que entiende y comprende sus necesidades de control de costos y servicio de calidad. Contamos con personal capacitado y con experiencia en el manejo de pasajeros, gestión de calidad, protocolos de seguridad, gestión de costos y presupuestos. Es una empresa seria, formal, empática, interesada en encontrar formas de mejorar el negocio de sus clientes convirtiéndose en su socio estratégico.

\subsection{Mercado objetivo}

Como ya hemos mencionado en líneas previas, el mercado está compuesto por empresas con base en Lima dedicadas al transporte de carga y de pasajeros. Dichas empresas pueden ser familiares o no familiares, con personal profesional o profesionalizado en base a su experiencia. Dado ello tienen características diversas que deben ser investigadas y entendidas para poder garantizar que la relación de nuestra empresa con los funcionaros de las empresas clientes pueda ser positiva y genere valor.

Nuestro mercado entonces formado por empresas, cuenta con agentes de decisión y estos son, según el tipo de empresas, los responsables de las jefaturas, gerencias o direcciones de transporte, operaciones y logística, según se perfilen los organigramas de las mismas. En algunos casos puede ser el mismo gerente general o dueño de la empresa quien decide los contratos y servicios con proveedores. En otros, estos puestos cuentan con profesionales de los campos de la ingeniería, administración 
o personas que han ganado experiencia en el mismo campo de trabajo, sin formación profesional. Del mismo modo, estos decisores pueden ser personal contratado externo o pertenecer| al mismo grupo familiar, en el caso de empresas familiares. Comprender estas relaciones es vital, ya que agrega alguna complejidad, más aún si quien es el decisor final es el dueño de la empresa.

No estamos considerando el mercado informal del transporte en nuestra propuesta, debido a que en una primera instancia debemos reducir la accidentabilidad en empresas formales, luego de ello y como una segunda gran parte de nuestro proyecto sería trabajar con empresas informales.

Lo común a todos los casos es que estas empresas busquen minimizar sus pérdidas, aumentar sus ganancias, controlar costos y ofrecer servicios diferenciados y de calidad, de tal forma que sus clientes los elijan asiduamente.

\subsubsection{Tendencia de mercado}

La tendencia del mercado apunta al crecimiento. Todos los años, como lo indican los cuadros del INEI, han sido valores positivos de crecimiento en el mercado automotor, la venta de unidades de carga y de pasajeros sigue en aumento, así como la generación de nuevas licencias de conducir de este tipo.

\subsubsection{Tamaño de mercado}

El tamaño de mercado estará compuesto por las empresas de transporte de carga y de pasajeros interprovincial. Podemos identificar a este tipo de empresas como las que utilicen unidades del tipo $\mathrm{M}_{2}, \mathrm{M}_{3}, \mathrm{~N}_{1}, \mathrm{~N}_{2}, \mathrm{~N}_{3}, \mathrm{O}_{2}, \mathrm{O}_{3}$ y $\mathrm{O}_{4}$ según normativa del MTC. Por otro lado, podemos también clasificar nuestro mercado potencial como la cantidad de licencias de conducir emitidas por el MTC mostradas en la tabla $\mathrm{N}^{\circ} 1.4$.

\subsubsection{Mercado objetivo}

Nuestro mercado objetivo o clientes potenciales son las empresas que tienen como propiedad más de 10 unidades, hacemos la salvedad que son empresas que tienen la 
propiedad a nombre de la empresa. Nuestro mercado objetivo lo mostramos en la Tabla 4.1 más adelante.

\subsubsection{Identificación de agentes (clientes, usuarios, compradores, prescriptores, intermediarios, mayoristas, minoristas, comisionistas)}

Clientes: empresas de carga o de transporte de personas, en este punto es vital conocer su tipo de organización e historia para poder establecer la forma en la que se debe abordar a los decisores.

Competidores: empresas que hoy están en el mercado de las capacitaciones en transporte y asesorías en transporte, si bien, como hemos mencionado, no existen empresas que den un servicio integral, si hay empresas que dan el servicio por partes.

Proveedores: en este caso los proveedores serían los conductores con experiencia que debemos contratar para los servicios de capacitación y que cuenten con ciertas habilidades en pedagogía y comunicación, esto lo desarrollamos más adelante.

Ministerio de Transportes/Ositran; como entes reguladores y fiscalizadores, es importante saber cómo su accionar afecta el servicio de nuestros clientes.

Ministerio de trabajo / SUNAFIL: como entes reguladores y fiscalizadores es importante saber cómo su accionar afecta el servicio de nuestros clientes.

Sindicatos: es común que en las empresas de transporte se encuentren sindicatos de trabajadores, por lo que hay que conocer su realidad para poder establecer nuestro servicio de manera efectiva.

Colaboradores: asesores y personal contratado para un proyecto determinado.

\subsubsection{Potencial de crecimiento del mercado}

El mercado de las empresas de asesorías es muy grande, sin embargo, son muy pocas las empresas que se dedican a la asesoría en el sector al que vamos a trabajar. Del mismo modo, en este momento no existe una empresa que brinde el servicio que nosotros planteamos, las barreras de entrada son relativamente bajas, por lo que profesionales con experiencia pueden generar proyectos empresariales como el nuestro en el mediano 
plazo, pero el mercado de transporte es tan amplio (Tabla 1.1) que tendremos un gran potencial de crecimiento.

\subsubsection{Rivalidad competidora y Potencial de ventas}

En el Perú no existen empresas de esta índole, por lo tanto, esta empresa se convierte en un proyecto innovador en donde vamos a entrar a un océano azul sin competidores. Sin embargo, el modelo es fácilmente replicable, por lo que es vital el que se puedan concretar contratos y relaciones de largo plazo con los clientes. Es por ello que la investigación y conocimiento de los clientes potenciales será fundamental en los planes comerciales.

Para establecer relaciones a largo plazo con los clientes, nos basaremos en los resultados obtenidos. Está garantizado que, al realizar una capacitación bajo los parámetros establecidos, la empresa de transporte tendrá un ahorro en costos por menores accidentes, ahorro en combustible y ahorro en el mantenimiento de la unidad; esto debe ser nuestra mejor presentación para establecer relaciones a largo plazo y para seguir mejorando estos valores.

\subsection{Desarrollo y estrategia del marketing mix}

\subsection{1 Política de gestión del cliente.}

Dado que nuestra empresa se dedica a la capacitación y tendremos actividades de asesoramiento también, la gestión del servicio al cliente es una pieza clave. Esta se iniciará desde la prospección de clientes, se debe contar con amplia información de la empresa a visitar, quiénes son los decisores en la misma y qué problemas pueda haber afrontado. Es primordial conocer esto para que se pueda ofrecer, desde la primera reunión, una asesoría personalizada y pueda entender las ventajas de nuestros servicios.

La prospección y atención del cliente será realizada por los ejecutivos senior de la empresa, experimentados en transporte, a fin de que puedan brindar información puntual sobre los problemas o necesidades de la empresa, según su realidad. Recordemos que el servicio que brindamos es personalizado a la empresa para que pueda optimizar sus costos a través de un mejor desempeño de sus conductores y un mejor manejo de sus tiempos en ruta. Los servicios que brindemos no pueden ser 
estándar, por lo que el acompañamiento al cliente es básico para generar confianza en el logro de sus objetivos.

\subsection{4.2 Estrategia de producto: especificaciones, calidad, variabilidad $\mathbf{y}$ diversificación.}

El servicio que brindaremos es el de capacitación y asesoría a empresas para optimizar sus costos directos y consumos de combustible adecuado por ruta. Esto traerá una importante disminución de costos, ayudará a gestionar la conducción correcta del vehículo que manejan y traerán disminución de costos en mantenimiento, los cuidados del mismo, el manejo de la carga que transportan, entre otros. Es por ello que nuestra empresa asesorará de forma específica y personal, dando soluciones a la medida respecto a las necesidades de las empresas de transporte de carga o de pasajeros.

Como ya hemos anotado, un atributo de calidad será el servicio brindado desde la prospección de clientes hasta la capacitación y el soporte de la misma posteriormente, vitales para que nuestra empresa genere confianza en el sector. Orto atributo de calidad será la profesionalización de nuestro personal, altamente capacitado e instruido para que difunda esto con el personal a capacitar o asesorar.

La ventaja competitiva de nuestro servicio radica en la experiencia y grado de customización que tenemos hacia el cliente.

\subsubsection{Estrategia de precios: análisis de costos y precios}

La estrategia de precios para los primeros 5 años no tendrán mayores ajustes porque, al ser un producto innovador y acompañando a la estrategia de formar alianzas con sus proveedores, no tendrán mayores variaciones. Por otro lado, los costos no se verán modificarlos, únicamente estamos considerando un ligero incremento en las remuneraciones. Los precios establecidos serán por horas, tanto de capacitación para el conductor, como la asesoría a las empresas en los temas ya mencionados; estos precios están desarrollados más adelante en la Tabla 7.6 de la proyección de ventas. Sin duda alguna, estamos considerando estos precios sin ajustes por la estabilidad económica que tenemos, pero cualquier exabrupto en nuestra economía nacional ameritaría un reajuste en base al acontecimiento. 


\subsubsection{Política comercial.}

La política comercial de la empresa está ligada a la customización del servicio. La empresa establecerá sus formas de fijación de precios dependiendo del tipo de servicio que se contrate y el grado de especificación que este requiera. Si bien se van a desarrollar paquetes de atención básicos, referidos a la evaluación de las necesidades de la empresa en base de horas trabajadas por el asesor principal, los servicios recomendados que se desarrollarían tendrán políticas comerciales basadas en el requerimiento en sí mismo.

\subsubsection{Estrategia comunicacional y canal.}

Al ser un servicio B2B, es decir, que se entrega de empresa a empresa, la estrategia de comunicación debe estar enfocada en los clientes que buscamos captar, por lo que se ha pensado en:

Estrategia relacional: esta se basa en el desarrollo de una base de datos de las empresas ubicadas como mercado objetivo primario, a las cuales nos acercaremos a través de contactos y gestionando información que les sea relevante, dirigida a las personas con poder de decisión en la empresa. Esta comunicación privilegiará los medios digitales para los primeros contactos. Como parte de esta estrategia es sustancial la gestión de contenido.

Estrategia de gestión de contenido: Dado que estamos ante un servicio B2B y que los decisores conocen muy a profundidad sus negocios, debemos establecer la autoridad, por la experiencia, que nuestra empresa posee y la forma en la que dicha experiencia apoyará a sus objetivos de rentabilidad. Esto se logrará a través de la gestión de la relación, utilizando contenidos que generen valor entre dichas personas. Para ello, se diseñará un mailing tipo clipping (noticias destacadas) que tengan que ver con el sector transporte e indicadores de interés para las empresas. Este contenido llegará primero como un boletín para suscripción gratuita y en forma semanal a los correos de los interesados. Del mismo modo, se utilizará la red de LinkedIn para enviar| diariamente información sobre el mundo del transporte y distribuir en la misma artículos de nuestros asesores sobre la realidad del transporte en el país, incidiendo en lo que hay que hacer para optimizar el mismo. Estas iniciativas tienen como fin establecer la experiencia, confianza y liderazgo en los temas a trabajar. Dentro de esta estrategia, se desarrollarán también video blogs, en donde los asesores darán su opinión o darán a 
conocer conceptos clave del sector. Toda esta estrategia se soporta en generar tráfico hacia la página web, en donde todos estos contenidos se encontrarán y algunos se ampliarán. Así mismo, como parte de la estrategia, se tendrá relacionamiento con medios, dirigidos al sector como revistas especializadas, para que nuestros asesores puedan ser referidos como voceros autorizados.

\subsubsection{Estrategia de distribución.}

El servicio que se busca brindar utilizará los medios digitales, con una estrategia focalizada en alcanzar a las personas que toman la decisión en las empresas. Del mismo modo, se buscará gestionar entrevistas personales con estos decisores para presentar a la empresa y los servicios que brindemos.

\subsection{Plan de Ventas (objetivos anuales, alcance de la oferta) y Proyección de la Demanda (crecimiento y desarrollo)}

Los principales objetivos del plan de ventas son los siguientes:

Plan de ventas a corto plazo, los primeros 6 meses:

- Desarrollar reuniones con contactos obtenidos por los medios electrónicos desarrollados.

- Generar contenidos para red social LinkedIn.

- Firmar 15 contratos e iniciar de operaciones.

Plan de ventas a mediano plazo, básicamente el primer año:

- Firmar 53 contratos e inicio de operaciones.

- Posicionarnos como líderes de segmento.

Plan de ventas a largo plazo, desde el segundo a quinto año:

- Cerrar los contratos señalados en el plan financiero

\subsubsection{Gestión de clientes}

En este sector, la gestión de la relación es clave, por lo que la búsqueda de clientes será desarrollada directamente por el gerente de la empresa, a través de reuniones gestionadas por los contactos obtenidos por los medios señalados para llevar el mensaje de la empresa. 


\subsubsection{Promoción de ventas}

Como ya se ha mencionado, se utilizarán medios sociales y digitales, para generar contacto y conocimiento de los servicios de la empresa. Así también, la estrategia de contenido busca posicionar al gerente de la empresa como líder del sector, relacionando su nombre al de la compañía.

\subsubsection{Servicios a ofertar}

Los servicios de la empresa son adaptados a las necesidades de los clientes, por lo que serán establecidos luego de la evaluación de la empresa partiendo de un servicio de capacitación en la propia empresa,para llegar hasta el desarrollo de planes y rutas específicas.

Los objetivos del plan de ventas están desarrollados en la Tabla 7.7.

\subsubsection{Proyección de la Demanda}

Proyectando los datos obtenidos del Ministerio de Transportes y Comunicaciones presentados en la tabla 1.1 y la Tabla 1.3, hemos obtenido una proyección a cinco años de la demanda de empresas para nuestro proyecto. Como se señaló al inicio de este capítulo, se buscará lograr $0.5 \%$ del total del mercado de empresas. Dado que no existen datos sobre el dimensionamiento de estas empresas, pero por conocimiento del sector, estimamos que es el $10 \%$ de las empresas con las características antes mencionadas. Dentro de este porcentaje se ubica el $0.5 \%$ que buscamos lograr. En la tabla 4.1 mostramos esta proyección.

Tabla 4.1: Proyección de demanda

\begin{tabular}{|lrrr|}
\multicolumn{1}{c}{ Cantidad de Unidades } & $\begin{array}{c}\text { Mercado total } \\
\text { año } 2016\end{array}$ & $\begin{array}{c}\text { Mercado } \\
\text { Disponible } \\
(\mathbf{1 0 \% )}\end{array}$ & $\begin{array}{r}\text { Mercado } \\
\text { Objetivo } \\
\mathbf{( 0 . 0 5 \% )}\end{array}$ \\
\hline Transporte de pasajeros - omnibuses & 10,183 & 1,018 & 5 \\
Transporte de carga - Camión y remolcador & 66,145 & 6,615 & 33 \\
TOTAL & 76,328 & 7,633 & 38 \\
\hline
\end{tabular}

Fuente: Elaboración Propia 


\section{CAPÍTULO V: Plan de operaciones}

\subsection{Políticas Operacionales}

Las políticas de operaciones estarán basadas en procesos y procedimientos estandarizados que nos ayudarán a normalizar los procesos y reducir los errores o variabilidad del servicio brindado, por lo cual pasamos a definir cada una de las siguientes variables.

\subsubsection{Calidad}

La organización entregará un servicio de buena calidad, eso significa, como explicamos en el párrafo anterior, tener estandarizados todos los procesos y tareas a realizar para eliminar o reducir la variabilidad en el servicio entregado. No estamos considerando alguna certificación en esta etapa inicial, ya que el presupuesto requerido excedería nuestra capacidad económica inicial, pero no por eso eximimos tener procesos normalizados.

\subsubsection{Procesos}

Los procesos serán estandarizados, debemos normar todos los procesos y actividades, tener procesos de inducción, capacitación y reforzamiento para que las personas en la organización tengan la claridad de cómo realizar las tareas, cuáles serán los registros y check list a cumplimentar.

Los procesos serán divididos en dos grupos importantes: los operacionales y los administrativos. En el primero, tendremos todos los procesos que regirán el buen funcionamiento del servicio a entregar; mientras que, por otro lado, tenemos las actividades de soporte para el buen funcionamiento de la organización internamente. 


\subsubsection{Planificación}

La planificación será un factor crítico de éxito, pues debemos identificar todos los requerimientos. El gerente de operaciones y el jefe de administración tendrán como función planificar todos los requisitos; y esto no es solo por tenerlos a tiempo, sino por prever los desembolsos necesarios en el futuro.

\subsubsection{Inventarios}

Los inventarios son un punto que no nos impactará directamente, ya que nuestra empresa será una de servicios; por ende, las compras a realizar serán mínimas, ya sean uniformes, equipos de protección personal como zapatos, cascos, guantes y materiales de limpieza para el mantenimiento de la oficina.

\subsection{Equipos, actividades y procesos}

\subsubsection{Localización, diseño y capacidad de instalaciones}

Para desarrollar los factores y tener un análisis de estos, estamos considerando criterios como:

- Determinación geográfica del grueso del mercado objetivo donde el departamento de Lima concentra casi el $50 \%$ de todo nuestro mercado por ende esta decisión de mantenerlo en esta región.

- Plan de Expansión y crecimiento. Como ya lo hemos mencionado también, el crecimiento que tendrá la empresa no requerirá en estos próximos cinco años un plan de expansión en la cual se incurra en una inversión en una nueva planta, ya que esto se dará luego de este plazo.

Para continuar con la búsqueda y evaluación de las ubicaciones hemos considerado como principales distritos Ate, Los Olivos y San Juan de Miraflores, básicamente porque:

- Son distritos con una gran concentración de empresas de transporte.

- Están cerca a las salidas de la ciudad de Lima. 
- La accesibilidad en precio de alquiler es económica.

- Son lugares donde también residen gran cantidad de personas que poseen licencia de conducir AIII.

Para definir la localización y diseño de las instalaciones primero debemos definir la ubicación geográfica de las oficinas, para lo cual hemos considerado la tabla 5.1 con el ranking de factores y con los resultados siguientes:

Tabla 5.1: Ranking de factores para la ubicación

\begin{tabular}{|l|l|l|l|l|l|}
\hline Lugar & Precio & al mercado & $\begin{array}{c}\text { sidencia de } \\
\text { clientes } \\
\text { finales }\end{array}$ & as de Lima & ultado final \\
\hline ivos & 4 & 4 & 4 & 3 & 3.75 \\
\hline $\begin{array}{c}\text { Juan de } \\
\text { Miraflores }\end{array}$ & 2 & 3 & 4 & 3 & 3.50 \\
\hline
\end{tabular}

Elaboración propia

Se ha utilizado una escala del 1 al 5, en la cual 1 tiene la menor injerencia o importancia, caso contrario el valor 5. Y la ponderación de cada variable ha sido de 33\%, es decir, cada variable tiene el mismo valor.

Finalmente, como resultado se obtuvo el distrito de Ate para definir la localización del lugar geográfico del proyecto.

\subsubsection{Equipos de trabajo y apoyos}

Los equipos de trabajo estarán conformados y liderados por el conductor instructor que tendrá a su cargo la capacitación de un grupo de conductores de los distintos clientes, él será responsable de capacitar e instruir y, por otro lado, informar los avances de sus capacitaciones al jefe de operaciones.

En la oficina estará el equipo de apoyo o soporte, quién será responsable de velar por todas las actividades que deben acompañar al buen funcionamiento de la organización, como son control de pagos de planillas, la parte contable, compras, entre otras. 


\subsubsection{Gestión de proveedores, compras y stock}

Como comentamos líneas arriba, las compras, los inventarios y la gestión de proveedores serán un punto que no nos impactará directamente, pues la organización es una empresa de servicios; por lo tanto, las compras a realizar serán mínimas, como uniformes, equipos de protección personal (zapatos, cascos, guantes) y materiales de limpieza para el mantenimiento de la oficina, la gestión de proveedores no será un punto crucial en la gestión de nuestra empresa.

\subsubsection{Tercerización o integración de procesos}

Por la magnitud de la organización que estamos planteando, sí requerimos tercerizar varias actividades de la organización, principalmente actividades como la contabilidad, tecnologías de la información, limpieza y mantenimiento. El motivo de ello, es que la magnitud de la empresa no justifica, en esta primera etapa, la contratación directa de estos servicios debido a que la carga laboral será mínima o de pocos días al mes.

\subsubsection{Implementación de las actividades por fases. Cadena de valor}

Esta cadena de valor describirá los procesos requeridos para que el negocio se desarrolle de manera adecuada y las variables para el servicio de capacitación estén controladas, en la tabla 5.2 mostramos estas actividades principales y de soporte.

Tabla 5.2: Cadena de valor

\begin{tabular}{|c|c|c|c|c|}
\hline \multicolumn{3}{|c|}{ Infraestructura de la empresa } \\
\hline \multicolumn{3}{|c|}{ Recursos Humanos } \\
\hline \multicolumn{3}{|c|}{ Soporte en tecnologías de información } \\
\hline Marketing & Operaciones & Capacitación & Ventas & Servicios \\
& & & & \\
\hline
\end{tabular}

Elaboración propia

\subsubsection{Proceso de prestación de servicio}


El proceso de prestación del servicio consistirá en capacitar e instruir a conductores en manejo seguro y manejo económico, desarrollar en conjunto con la empresa hojas de rutas, itinerarios, descansos, rotaciones semanales del personal, entre otros. El servicio a entregar para todos los clientes será diferente, porque todos tienen características diferentes del servicio tanto de pasajeros como de carga. Inacabable resultaría intentar plasmar en un documento las respuestas para cada servicio. Por esto, se está considerando establecer un proceso por el cual cada entregable al cliente sea revisado por el jerárquico superior, es decir, primero por el coordinador de transporte y luego por el gerente de operaciones.

\subsubsection{Políticas de transformación de la actividad}

5.2.9 Básicamente nuestra principal transformación al ser un servicio, consistirá en la capacitación a los conductores de los clientes, tendremos políticas y procesos que indicarán el camino o la ruta para determinar necesidades de capacitación, como son conocimiento de la unidad, conocimiento de los parámetros de manejo, atención al cliente, entre otras.

\section{2 .10}

\subsubsection{Flujograma de la actividad y Diagrama de decisiones PERT}

Definir las operaciones: Definimos las siguientes actividades para realizar la implementación del proyecto, mostradas en la tabla 5.3:

- Constitución de la empresa.

- Obtener financiamiento.

- Trámites de licencias.

- Seleccionar al personal.

- Entrenar al personal.

- Comprar mobiliario.

- Comprar computadoras, equipos de comunicación.

- Comprar uniformes y equipos de protección personal.

- Contratación terceros en sistemas.

- Puesta en marcha.

Establecimiento de actividades precedentes y tiempos, mostrado en la tabla 5.4. 
A continuación mostramos la lista de actividades para llevar a cabo el proyecto con sus actividades predecesoras y tiempos estimados a desarrollar:

Tabla 5.3: Actividades requeridas para la puesta en marcha

\begin{tabular}{|l|c|c|c|}
\hline \multicolumn{2}{|c|}{ Actividad } & dad predecesora & $\begin{array}{c}\text { Tiempo } \\
\text { (días) }\end{array}$ \\
\hline A & Constitución de la empresa & & 18 \\
\hline B & Obtener financiamiento & A & 14 \\
\hline C & Trámites de licencias & B & 32 \\
\hline D & Seleccionar personal & B & 14 \\
\hline E & Entrenar al personal & C,D & 8 \\
\hline F & Comprar mobiliario & B & 15 \\
\hline G & prar computadoras, equipos de & B & 3 \\
\hline H & comunicación & & 5 \\
\hline I & mprar uniformes y equipos de & B & 1 \\
\hline J & Pratación terceros en sistemas & G & 5, H \\
\hline
\end{tabular}

Elaboración propia

Definición de tiempos optimista y pesimista con el cálculo del tiempo estimado según fórmula:

$$
\mathrm{Te}=[(1 / 6) \cdot(\mathrm{a}+4 \cdot \mathrm{m}+\mathrm{b})]+[(\mathrm{b}-\mathrm{a}) \cdot(\mathrm{V} / 6)]
$$

Tabla 5.4: Tiempos requeridos para la puesta en marcha

\begin{tabular}{|l|l|l|l|l|}
\hline Actividad & TO & TM & TP & TE \\
\hline
\end{tabular}




\begin{tabular}{|c|c|c|c|c|}
\hline A & 16 & 18 & 22 & 18.3 \\
\hline B & 8 & 14 & 20 & 14.0 \\
\hline C & 24 & 32 & 60 & 35.3 \\
\hline D & 10 & 14 & 25 & 15.2 \\
\hline E & 7 & 8 & 12 & 8.5 \\
\hline F & 10 & 15 & 18 & 14.7 \\
\hline G & 2 & 3 & 5 & 3.2 \\
\hline H & 3 & 5 & 8 & 5.2 \\
\hline I & 2 & 3 & 6 & 3.3 \\
\hline J & 1 & 1 & 1 & 1 \\
\hline
\end{tabular}

Elaboración propia

A continuación mostramos la representación del diagrama de red:

Figura 5.1: Representación del diagrama vectorial o red

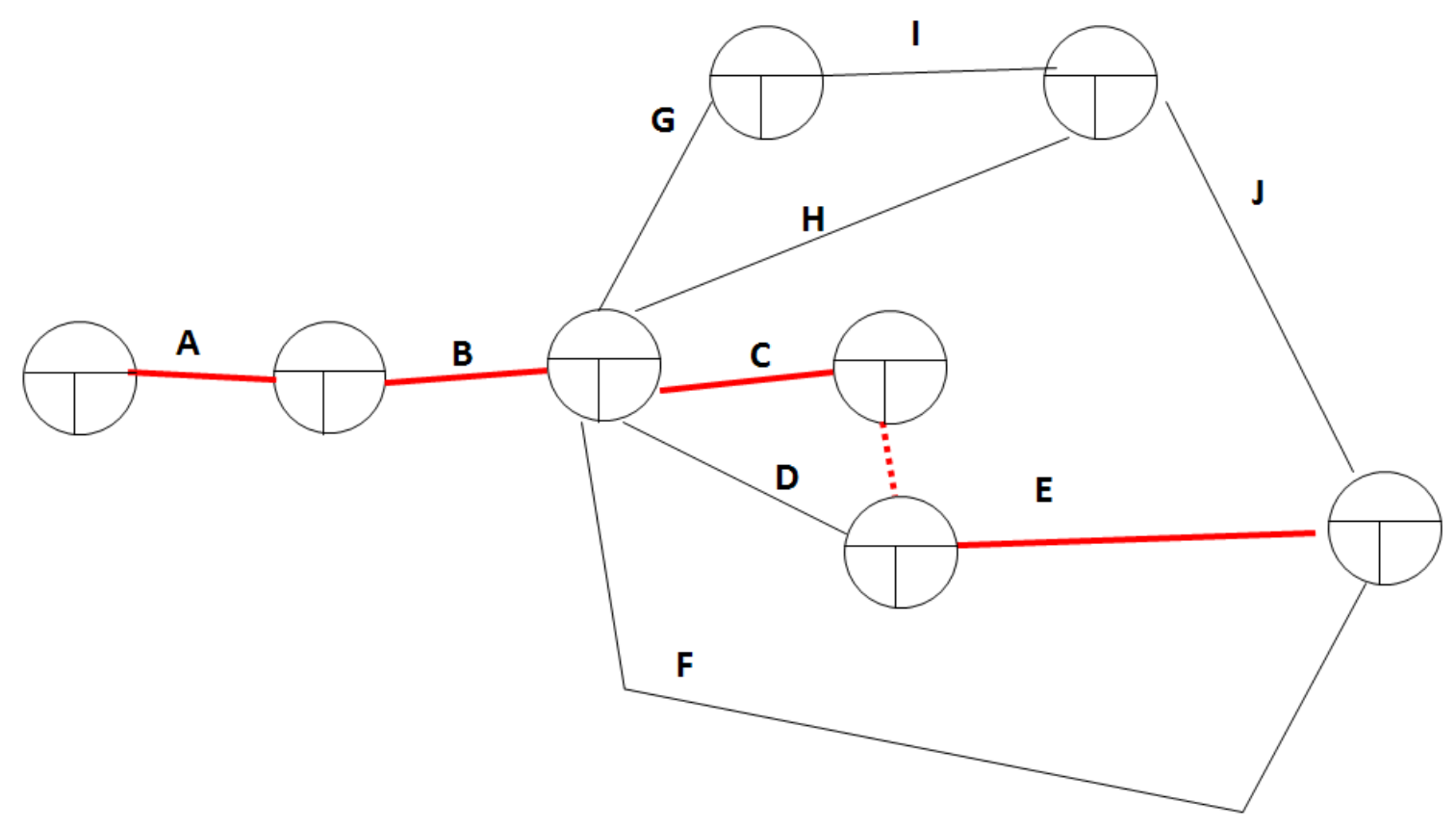

Elaboración propia 
Determinar el plazo final del proyecto por el método del camino crítico representado en la figura 5.2:

Figura 5.2: Representación del diagrama vectorial o red con tiempos

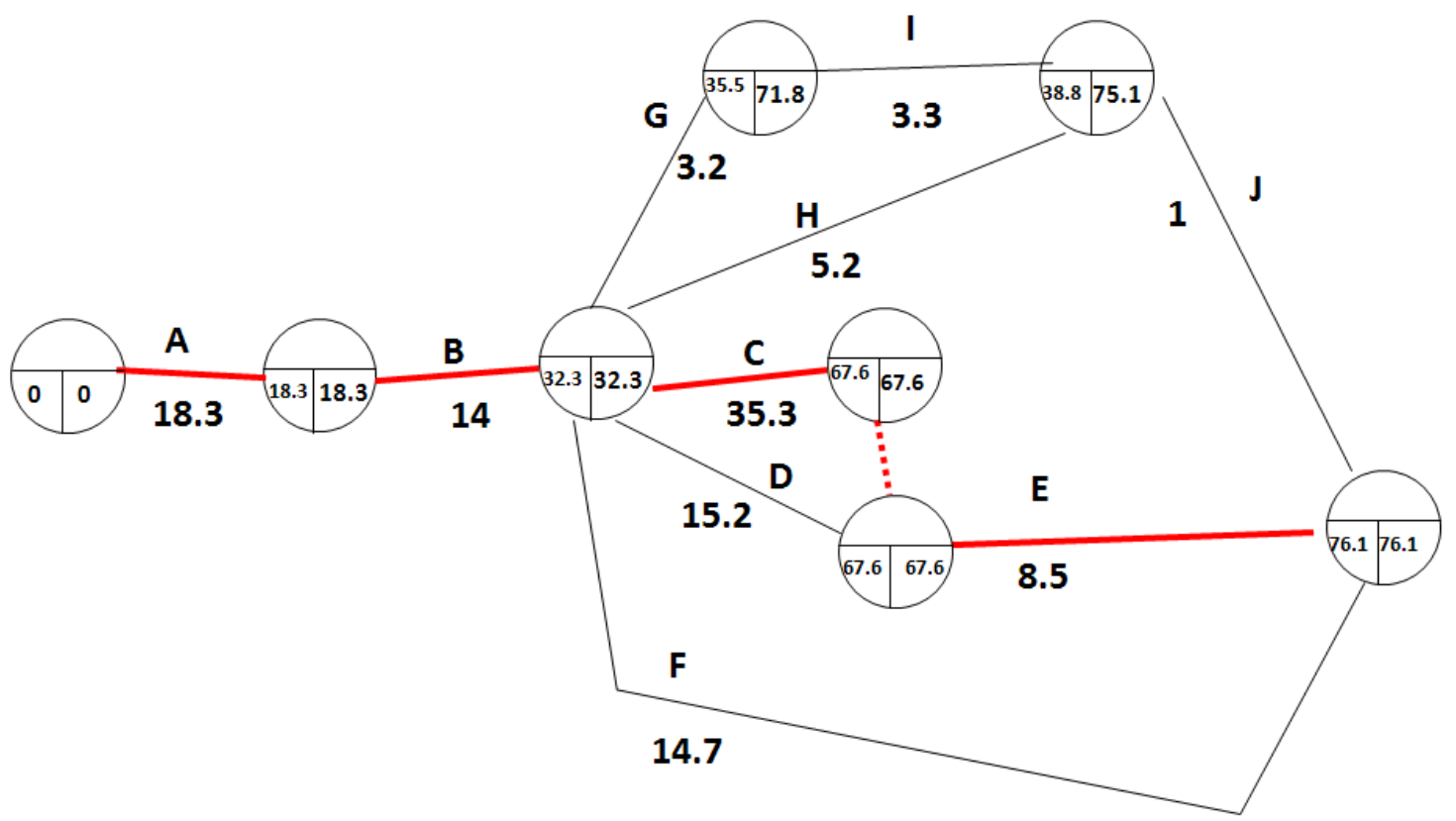

Elaboración propia

Buscamos la posibilidad de reducir el plazo total del proyecto, pero incurriremos en mayores gastos, se ha corrido el proyecto con el uso de Microsoft Project mostrados en la figura 5.4 definiendo los siguientes resultados sin ningún costo adicional porque dependerá de la actividad que uno desee disminuir en tiempo. 
Figura 5.3: Cronograma del proyecto en Microsoft Project

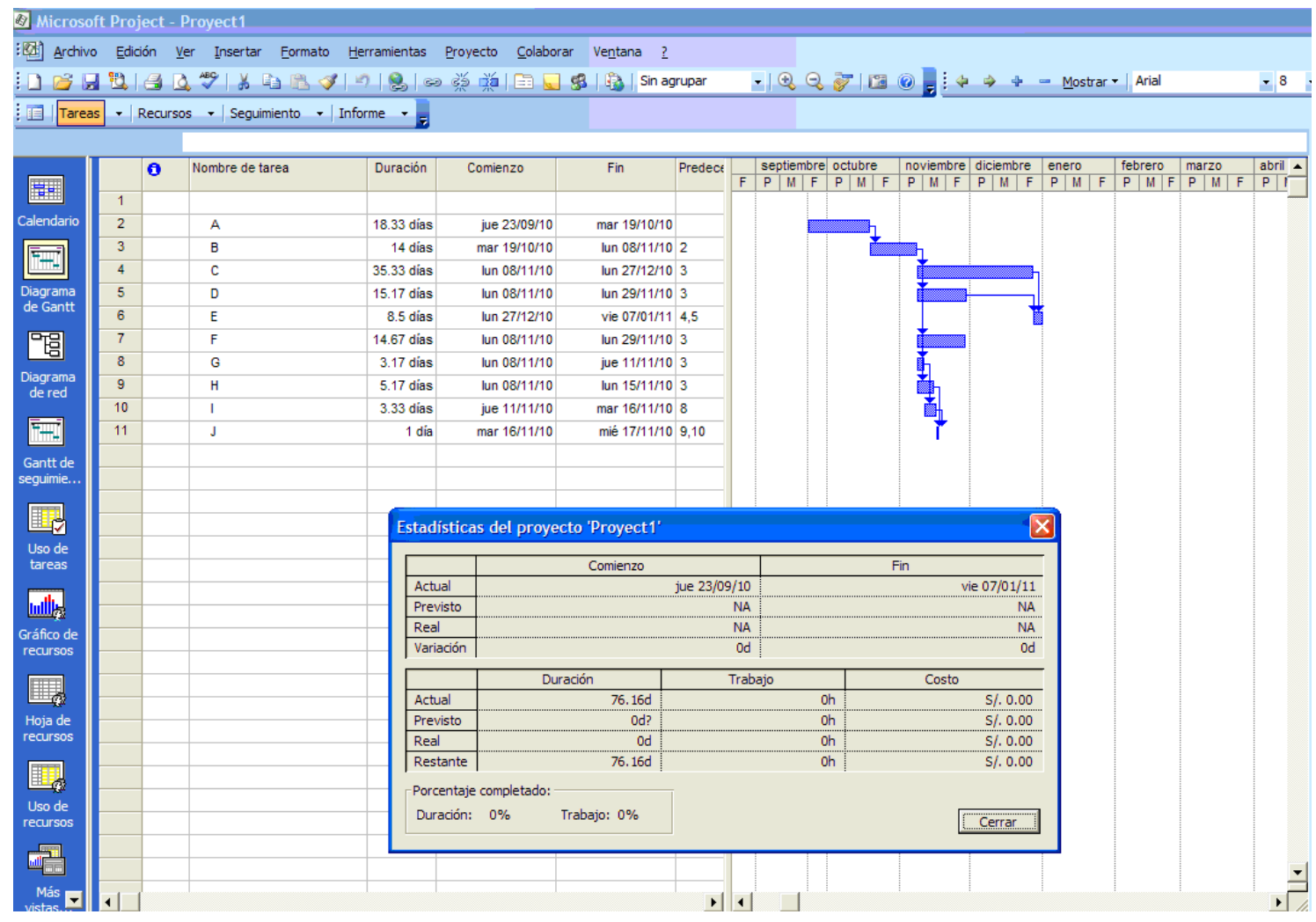

Elaboración propia

\subsubsection{Balance Scorecard: Control de gestión por indicadores}

5.2.13 Toda nuestra gestión estará controlada por indicadores de gestión que medirán y nos informarán de manera constante los criterios más importantes.

Consideraremos como los principales indicadores los siguientes:

- Beneficio neto / utilidad neta

- ROI

- Conductores capacitados por instructor

- Satisfacción del cliente

- Número de accidentes por millón de kilómetros en empresas capacitadas 5.2 .14

\subsubsection{Marco Legal}


En el marco legal de la constitución de la empresa consideraremos crear una Empresa Individual de Responsabilidad Limitada, consideramos tener mayores ventajas que desventajas. La ley 19.857, publicada en el Diario Oficial el 11 de febrero del 2003, autoriza el establecimiento de las empresas individuales de responsabilidad limitada (E.I.R.L).

Dentro de este análisis pasamos a identificar las siguientes ventajas de este tipo de empresas:

- No necesitaremos conseguir un socio nominal para establecer el límite de responsabilidad de las deudas por la gestión comercial que haremos.

- Separaremos con la creación de la EIRL el patrimonio propio y el patrimonio de la empresa.

- Según nuestros ingresos el tratamiento tributario es más beneficioso. Ello porque la base impositiva para contribuyentes de primera categoría es más baja que para las personas naturales (si haces retiros de la EIRL los retiros los tendrás que tributar eso sí bajo reglas de global complementario, volviendo a las normas de personas naturales).

Igualmente podemos definir algunas desventajas para este tipo de empresas según nuestro proyecto:

- Tendremos un mayor costo en la gestión del negocio, puesto que debemos contratar un contador, por eso, seguidamente, estamos considerando contratar a un service de contabilidad

- La ley dice que la EIRL es comercial, por ende, las reglas de quiebra son distintas para comerciantes respecto de los no comerciantes. Por otra parte, las normas laborales aplicables a empresas comerciales generan, por ejemplo, la obligación de pagar gratificaciones considerado en nuestro análisis más adelante.

- Además en términos tributarios, nos convertimos en agente retenedor de tributos. 


\section{CAPÍTULO VI: ESTRUCTURA ORGANIZACIONAL Y RECURSOS HUMANOS}

\subsection{Objetivos Organizacionales}

Los objetivos organizacionales estarán compuestos por varios factores críticos de éxito, ¿ofrecer servicios ágiles que no incurran en demoras ni sobrecostos a los clientes. Otro objetivo empresarial será tener más del $90 \%$ de clientes cautivos que regresen por más servicios. Otro objetivo organizacional será tener como mínimo tener 150 horas de capacitación por año por conductor-instructor.

\subsubsection{Naturaleza de la Organización}

La naturaleza de la organización estará basada según la reglamentación nacional vigente decretado por el Ministerio de Trabajo y Promoción del Empleo según D.S. No 039-91TR y a la vez consideraremos el Reglamento de Seguridad y Salud en el Trabajo según Ley $N^{\circ} 27711$.

\subsubsection{Organigrama}

El diseño organizacional se presenta en la Figura $\mathrm{N}^{\circ} \mathbf{7 . 1}$, en el cual se busca principalmente un flujo rápido de la información, pocos niveles jerárquicos con el fin de que las decisiones se puedan tomar de una manera más ágil. 
Figura 7.1: Organigrama de la empresa

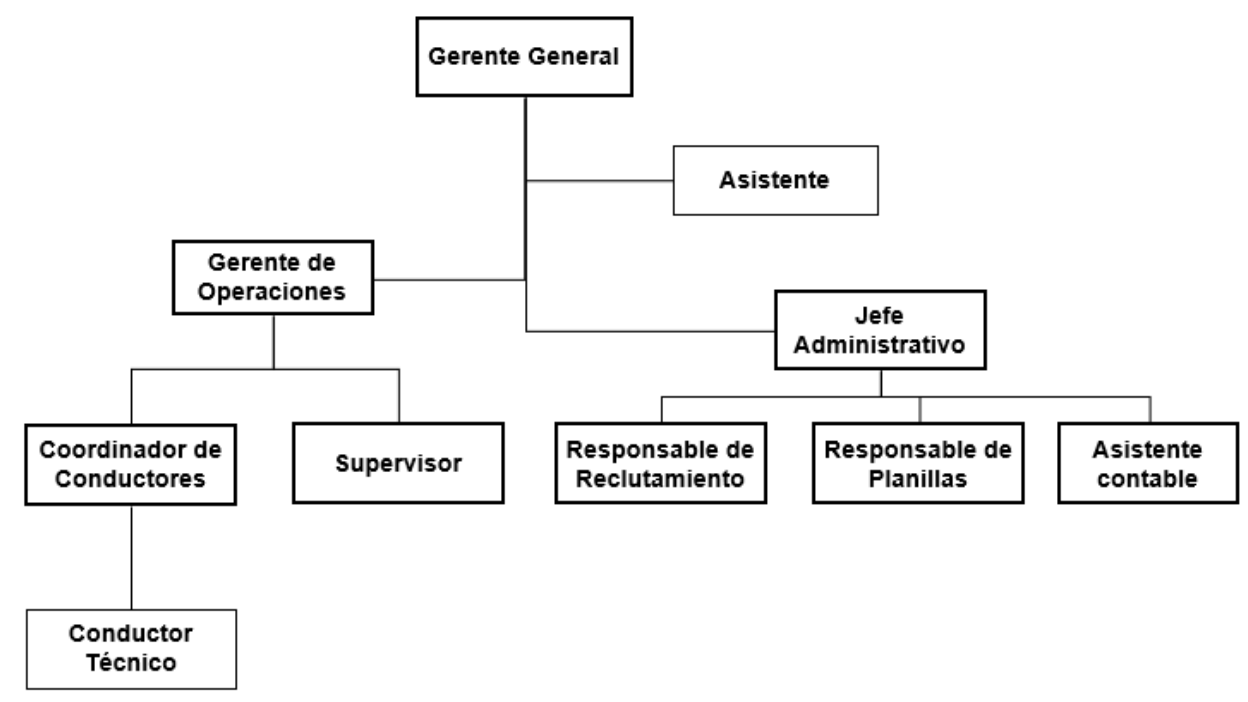

Elaboración propia

\subsubsection{Diseño estructural por proyectos}

Como se muestra en el organigrama, la Gerencia de Operaciones estará a cargo del core business de la organización, en ella recaerán las principales responsabilidades del servicio de capacitación y soporte a empresas de transporte, con las líneas de negocio antes mencionadas. El gerente será el encargado de desarrollar los proyectos en base a los requerimientos solicitados por el cliente y calcular la cantidad de recursos requeridos.

Las otras áreas de la organización serán soporte, como ya lo hemos comentado, pero que son requeridas para el normal desenvolvimiento de la empresa.

\subsection{Diseño de Puestos y Responsabilidades}

El diseño de puesto se ha realizados según el organigrama anterior y el manual y los perfiles de cada puestos están en el Anexo I

\subsection{Políticas Organizacionales}

Sobre las políticas organizacionales tenemos generales y específicas, que se requerirán para establecer los lineamientos que tendremos en la organización. Primero mencionaremos las políticas generales, como son: 
- Políticas de comportamiento en la organización.

- Políticas de calidad.

- Políticas de responsabilidad sobre los activos de la empresa.

- Políticas de atención a los clientes.

- Política de Seguridad y Salud en el trabajo.

- Políticas éticas

Por otro lado, tendremos las políticas específicas como son:

- Políticas de pagos a los proveedores.

- Políticas de asignación de viáticos para los viajes.

- Políticas de gestión de la información.

\subsubsection{Política de fidelización de capacitadores}

Las políticas de fidelización de los capacitadores consistirán en brindarles el empowerment necesario para que tengan libertad de realizar sus labores de la mejor manera. Como ya hemos capacitado y certificado a nuestros conductores, debemos considerar que realizarán sus labores de la mejor manera. Consideramos que el empowerment es la mejor manera de fidelizarlos, de empoderarlos en sus labores y tenerlos dentro de nuestras actividades. No hemos considerado un incremento en sus ingresos, como medio de fidelización por no ser una práctica recomendada.

\subsubsection{Certificación Internacional de Conductores}

Proponemos una certificación internacional para los conductores capacitadores, esta certificación no se dará desde un inicio, se evaluará el impacto, los costos, la necesidad de los clientes por esta certificación. Para ello, se ha considerado optar por el "Centro de Investigación y Formación para el Transporte y la Seguridad Vial" de Uruguay, ellos certifican a conductores tanto en el transporte de carga como transporte de pasajeros. Esta institución tiene un programa que nos podría ayudar para complementar el comportamiento, forma de enseñanza y perfiles de los conductores capacitadores.

\subsection{Gestión del talento}

\subsubsection{Selección y contratación}


Para la selección y contratación requerimos de un psicólogo que pueda evaluar a todos los postulantes y contratar a los más idóneos, el perfil para cada puesto ya fue descrito líneas arriba y esta persona debe centrarse en buscar aquellos que manifiesten buen servicio al cliente, que tengan perfiles de andragogía (si bien este punto se irá desarrollado en las capacitaciones internas) o habilidades de comunicación y/o enseñanza.

\subsubsection{Remuneración y desempeño}

La estructura salarial está considerada como un sueldo fijo, no estamos considerando un sueldo variable porque el proyecto es nuevo y podría presentar problemas. Si eso se ve reflejado en el sueldo del personal podrían optar por retirarse. Como está analizado en el análisis FODA, una de nuestras debilidades es que el personal técnico migre a otras empresas y como las acciones que mitigan esto, está el tener remuneraciones por encima de la media del mercado como se muestra en la Tabla $\mathrm{N}^{\circ} 6.1$.

Las remuneraciones que hemos considerado son las siguientes:

Tabla $N^{\circ}$ 6.1: Remuneraciones del Personal

\begin{tabular}{|l|c|}
\hline \multicolumn{1}{|c|}{ Puesto } & Remuneración (S/.) \\
\hline Gerente General & 5,500 \\
\hline Gerente de Operaciones & 5,000 \\
\hline Coordinador & 3,500 \\
\hline Supervisor & 2,000 \\
\hline Conductor Técnico & 2,500 \\
\hline Jefe de Administración & 3,500 \\
\hline Responsable de reclutamiento & 2,500 \\
\hline Responsable de planillas & 2,500 \\
\hline Asistente contable & 1,500 \\
\hline Asistente & 1,000 \\
\hline
\end{tabular}


Elaboración Propia

Cabe señalar que todo este personal no empezará desde el mes 1, se irán incorporando a medida que vayan creciendo las operaciones y como se verán en las tablas más adelante.

\subsubsection{Empowerment y reconocimiento}

Dentro de la organización se tendrá una política de reconocimiento y empowerment, ya que los conductores instructores estarán capacitando a conductores en diferentes partes del país y ellos tendrán la libertad y confianza de no tener una supervisión directa, si bien ellos reportarán al coordinador de conductores jerárquicamente, tendrán las facilidades de tomar las mejores decisiones sobre los lineamientos establecidos en la enseñanza.

Finalmente, habrá también una programa de reconocimiento anual al trabajador del año donde se premiará al personal que, por votación de los integrantes de la empresa, haya mostrado mayor compromiso, apoyo y visión en sus labores del día a día y que se hará acreedor a un reconocimiento por parte de la gerencia general.

\subsubsection{Capacitación, motivación y desarrollo}

Una de nuestras principales funciones será la capacitación y enseñanza a conductores de otras empresas que requieren mejorar sus habilidades en el manejo de unidades de transporte de carga y buses; por ello, la capacitación constante a nuestro personal será una labor del día a día, ya que será una de nuestras fortalezas. El conocimiento no solo técnico, sino también en habilidades blandas es primordial, ya que ellos deberán conocer sobre andragogía, pedagogía, atención al cliente, entre otros. Haremos capacitaciones constantes mediante un cronograma sobre aspectos técnicos (convenios con empresas comercializadoras de camiones y buses) y sobre aspectos de atención al cliente, enseñanza, empatía, de la mano con instituciones y profesores que puedan desplegar no solo de manera presencial sino también de manera virtual. De esa manera, otros aspectos serán constantemente reforzados.

\subsection{Estructura de gastos de RRHH}


La estructura de gastos en recursos humanos estará centrada en los conductores capacitadores, ellos serán nuestro gran equipo que trabajará con los clientes constantemente. Por otro lado, tendremos también la fuerza de ventas, conformada por aquellos que ofrezcan y cierren el proceso de ventas. Estos montos sobre los gastos lo desarrollamos en la Tabla 7.8. 


\section{CAPÍTULO VII: PLAN ECONÓMICO-FINANCIERO}

\subsection{Supuestos}

Los principales supuestos para la evaluación del siguiente proyecto son los siguientes:

- El horizonte de evaluación es de cinco años y los flujos presentados y desarrollados serán de manera anual.

- El presupuesto de ventas tiene un incremento ligero de manera anual en los cinco años según el pronóstico considerado.

- Se evalúa el proyecto solo con los servicios descritos en los puntos previos, si bien se puede hacer una mayor cobertura del negocio, se mantiene una relación conservadora.

- En la proyección de ingresos y gastos se emplea moneda constante; es decir, los precios y costos futuros mantendrán la misma relación numérica.

\subsection{Plan de Inversiones}

El plan de inversiones estará en función al crecimiento del negocio, al captar nuevas empresas de transporte excedentes a lo planificado, requerimos nuevas inversiones, por tanto, para los cinco primeros años solo hemos considerado lo planificado en la Tabla 7.1.

En la Tabla 7.1 mostramos la inversión que nos cubrirá para los 5 años. 
Tabla 7.1 Plan de requerimiento de activo fijo para las operaciones

\begin{tabular}{|c|c|c|c|c|c|c|}
\hline Inversión & Año 0 & Año 1 & Año 2 & Año 3 & Año 4 & Año 5 \\
\hline Computadoras & 20,790 & & & & & \\
\hline Multifuncional & 2,640 & & & & & \\
\hline Camioneta & 89,100 & & & & & \\
\hline Escritorios & 7,850 & & & & & \\
\hline Muebles & 4,500 & & & & & \\
\hline Cámaras fotográficas & 990 & & & & & \\
\hline Licencias (software) & 2,310 & & & & & \\
\hline Total Acumulado & 128,180 & 0 & 0 & 0 & 0 & c \\
\hline & & & & & & \\
\hline Inversión con IGV & Año 0 & Año 1 & Año 2 & Año 3 & Año 4 & Año 5 \\
\hline Computadoras & 24,532 & & & & & \\
\hline Multifuncional & 3,115 & & & & & \\
\hline Camioneta & 105,138 & & & & & \\
\hline Escritorios & 9,263 & & & & & \\
\hline Muebles & 5,310 & & & & & \\
\hline Cámaras fotográficas & 1,168 & & & & & \\
\hline Licencias (software) & 2,726 & & & & & \\
\hline & & & & & & \\
\hline Total Acumulado (con IGV) & 151,252 & & & & & \\
\hline Elaboración propia & & & & & & \\
\hline
\end{tabular}

A continuación, considerando el activo fijo y los intangibles que se requerirán para el proyecto, así como para la puesta en marcha de la empresa, se presenta el plan total de inversiones en la Tabla $\mathrm{N}^{\circ} 7.2$.

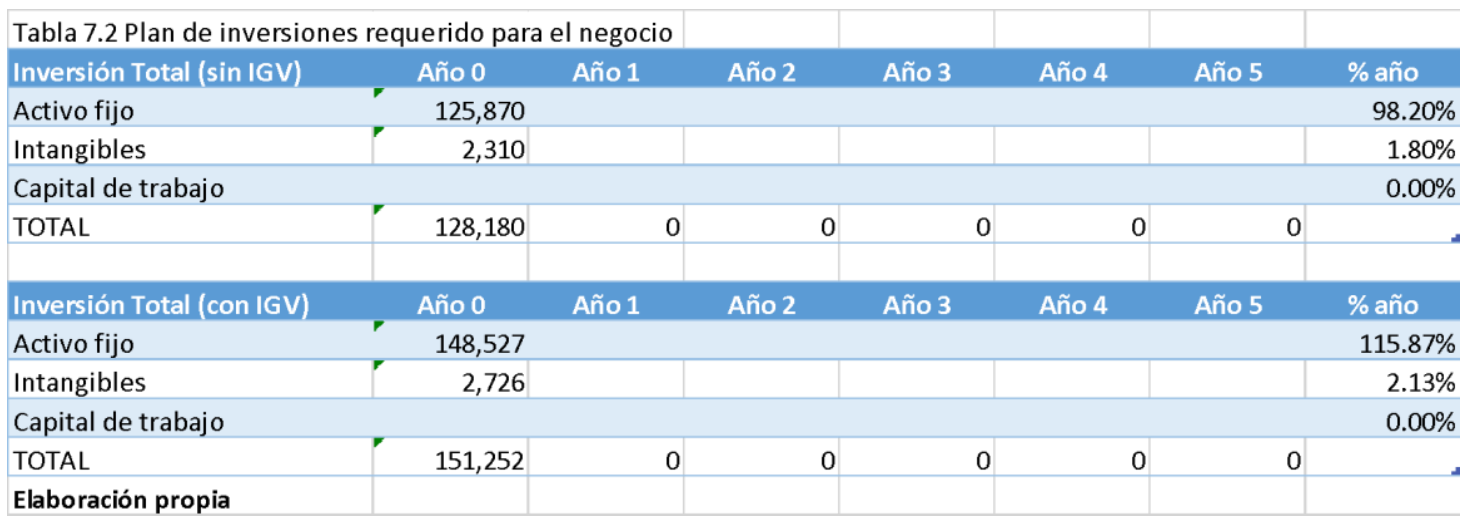

En los costos de inversión más elevados se pueden apreciar en el activo fijo que corresponde al $98.20 \%$, y los intangibles solo menos del $2 \%$, que son la marca, la publicidad y la campaña de lanzamiento para la puesta en marcha del negocio.

Sin embargo y por más que quisiéramos eliminarlos, no se podría, ya que son imprescindibles. Nuestra página web servirá como primer paso de contacto con nuestra 
empresa y la campaña de lanzamiento para comenzar a hacer la publicidad y poder darnos a conocer.

\subsection{Activos y depreciación}

Para considerar la depreciación y la amortización de intangibles, emplearemos una vida fiscal de cinco años, como lo desarrollaremos a lo largo de este capítulo. En la tabla 7.3 presentamos la depreciación y amortización durante el horizonte señalado, tanto para los activos fijos de operación, administración y la amortización de intangibles.

7.3 Amortización y depreciación

\begin{tabular}{|c|c|c|c|c|c|c|}
\hline & Año 0 & Año 1 & Año 2 & Año 3 & Año 4 & Año 5 \\
\hline Depreciación Activo fijo & & 25,174 & 25,174 & 25,174 & 25,174 & 25,174 \\
\hline Amortización Intangibles & & 462 & 462 & 462 & 462 & 462 \\
\hline Total S/. & & 25,636 & 25,636 & 25,636 & 25,636 & 25,636 \\
\hline Total acumulada S/. & & 25,636 & 51,272 & 76,908 & 102,544 & 128,180 \\
\hline
\end{tabular}

Elaboración propia

\subsection{Capital de trabajo}

Como una de las políticas que implementaremos, haremos que las cobranzas se hagan efectivas una vez culminado el servicio, para lo cual se prevé usar cuentas bancarias electrónicas. De igual forma, hemos considerado que puede presentarse un desbalance en el cobro versus lo planteado hasta en 20 días para cubrir responsabilidades de pago que se pudieran presentar.

\subsection{Fuentes de financiamiento y amortización}

Después de tener los montos de inversión, se ha decidido realizar la inversión solo con capital propio y no requerir de entidades financieras del sistema. Por ende, el riesgo solo será asumido por el propietario.

\subsection{Balances previsionales}

El modelo financiero que emplearemos en la evaluación permite el cálculo del balance general, que está presentado en la Tabla 7.4. 


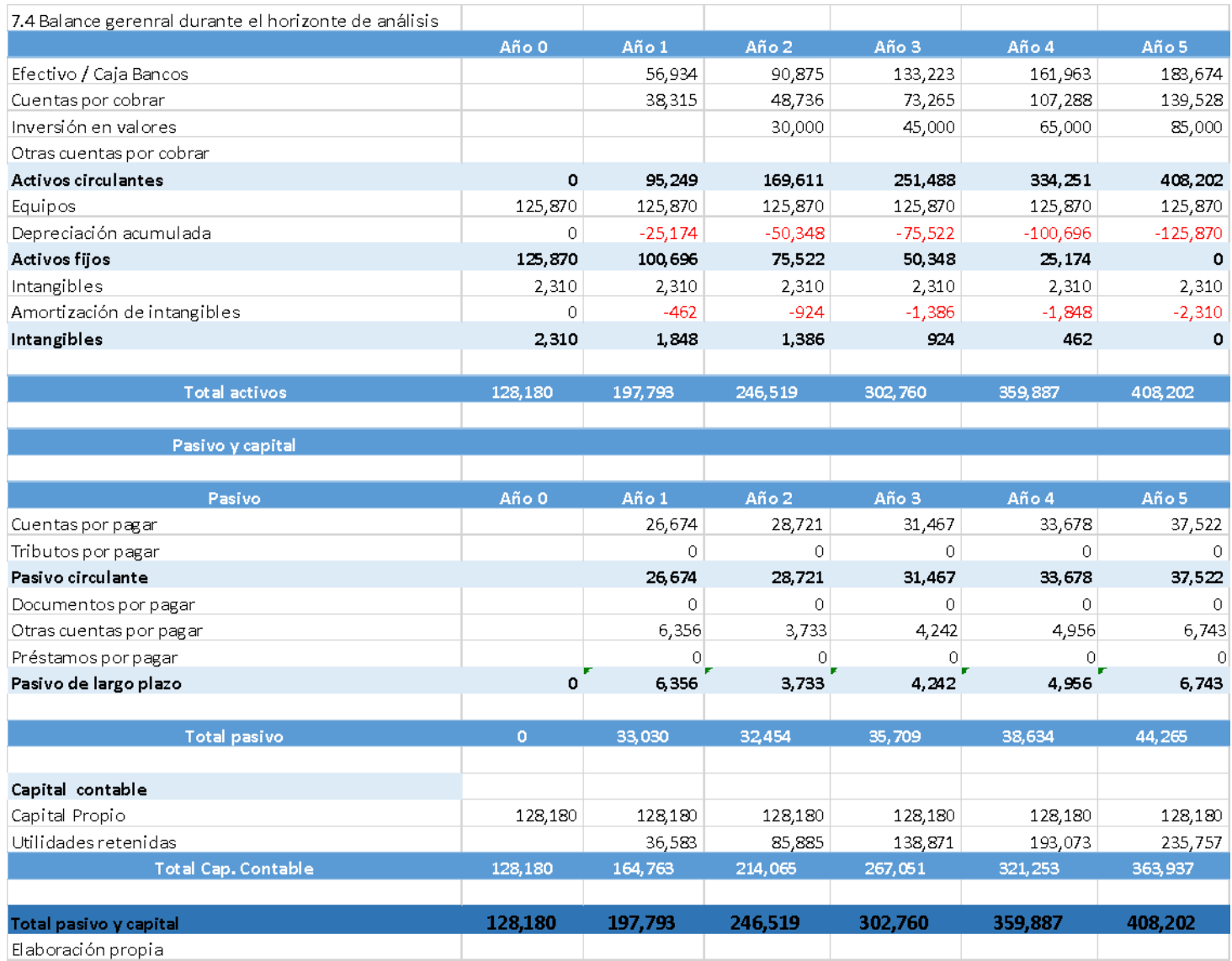

\subsection{Cuentas de exploración previsionales (GGPP)}

En el siguiente Tabla $N^{\circ} 7.5$ mostramos el estado de resultados que tendrá la empresa en los siguientes 5 años.

\begin{tabular}{|c|c|c|c|c|c|}
\hline \multicolumn{6}{|l|}{ 7.5 Estado de Resultados } \\
\hline & Año 1 & Año 2 & Año 3 & Año 4 & Año 5 \\
\hline Ventas & 750,000 & 818,000 & 928,800 & $1,027,000$ & $1,173,000$ \\
\hline - Personal de operaciones & $-236,794$ & $-244,716$ & $-273,595$ & $-291,866$ & $-306,814$ \\
\hline - Gastos de Operación & $-127,659$ & $-137,342$ & $-144,148$ & $-175,689$ & $-198,978$ \\
\hline =Margen Burto & 385,547 & 435,942 & 511,058 & 559,445 & 667,209 \\
\hline - Gastos Administrativos & $-145,674$ & $-161,150$ & $-190,954$ & $-217,543$ & $-254,288$ \\
\hline - Gastos de Venta & $-123,521$ & $-136,893$ & $-156,354$ & $-195,370$ & $-257,260$ \\
\hline$=$ =Utilidad Operativa (EBITDA) & 116,352 & 137,899 & 163,750 & 146,532 & 155,661 \\
\hline $\begin{array}{l}=- \text { Depreciación y Amortización de } \\
\text { intngibles }\end{array}$ & $-25,636$ & $-25,636$ & $-25,636$ & $-25,636$ & $-25,636$ \\
\hline Utilidad antes de impuestos (EBIT) & 90,716 & 112,263 & 138,114 & 120,896 & 130,025 \\
\hline - Gastos financieros & $-38,454$ & $-28,200$ & $-40,377$ & $-12,818$ & $-9,614$ \\
\hline UTILIDAD ANTES DE IMPUESTOS & 52,262 & 84,064 & 97,737 & 108,078 & 120,411 \\
\hline Impuesto a la Renta & $-15,679$ & $-25,219$ & $-29,321$ & $-32,423$ & $-36,123$ \\
\hline$=$ Utilidad Neta & 36,583 & 58,845 & 68,416 & 75,655 & 84,288 \\
\hline Elaboración propia & & & & & \\
\hline
\end{tabular}




\subsection{Proyección de Ventas y Flujo de Tesorería (Cash flow)}

Las ventas y precios de venta, como ya lo hemos comentado, han sido proyectados a cinco años, teniendo en consideración los posibles escenarios futuros que se puedan presentar, como la incorporación de competencia, empresas que den servicios de capacitación en aula y quieran salir a realizar capacitaciones como el nuestro, o empresas que vendan unidades de transporte de carga/ de pasajeros y quieran ampliar su postventa a un servicio similar al nuestro.

Tendremos también dos tipos de ingresos: el principal será la capacitación de conductores, para lo cual hemos estimado un precio de S/. 50 el día. Así también, que un conductor capacitado requerirá 21 días, y la asesoría a las empresas donde estamos considerando S/. 50 la hora de asesoría.

En la Tabla 7.6 mostramos por ende la planificación considerando estos supuestos.

\begin{tabular}{|c|c|c|c|c|c|}
\hline \multicolumn{6}{|l|}{ Tabla 7.6: Proyección de ventas } \\
\hline & Año 1 & Año 2 & Año 3 & Año 4 & Año 5 \\
\hline Ventas por capacitación ( $\mathrm{N}^{\circ}$ conductores) & 600 & 660 & 756 & 840 & 960 \\
\hline Precio de venta por día (S/.) & 50 & 50 & 50 & 50 & 50 \\
\hline Número de días & 21 & 21 & 21 & 21 & 21 \\
\hline Sub-total & 630,000 & 693,000 & 793,800 & 882,000 & $1,008,000$ \\
\hline Asesoría a empresa de transporte (horas) & 2,400 & 2,500 & 2,700 & 2,900 & 3,300 \\
\hline Precio de venta $(S /)$. & 50 & 50 & 50 & 50 & 50 \\
\hline Sub-total & 120,000 & 125,000 & 135,000 & 145,000 & 165,000 \\
\hline Ingresos por ventas & 750,000 & 818,000 & 928,800 & $1,027,000$ & $1,173,000$ \\
\hline Ingresos por ventas (Inc. IGV) & 885,000 & 965,240 & $1,095,984$ & $1,211,860$ & $1,384,140$ \\
\hline Elaboración Propia & & & & & \\
\hline
\end{tabular}

Del mismo modo y considerando la proyección de ventas de la tabla anterior, se presenta el flujo de caja en la Tabla $\mathrm{N}^{\circ} 7.7$. 


\begin{tabular}{|c|c|c|c|c|c|c|}
\hline & Año 0 & Año 1 & Año 2 & Año 3 & Año 4 & Año 5 \\
\hline Ingreso por ventas & & 885,000 & 965,240 & $1,095,984$ & $1,211,860$ & $1,384,140$ \\
\hline Gastos del personal de operaciones & & $-236,794$ & $-244,716$ & $-273,595$ & $-291,866$ & $-306,814$ \\
\hline Gastos de operación & & $-127,659$ & $-137,342$ & $-144,148$ & $-175,689$ & $-198,978$ \\
\hline Gastos del personal de administración & & $-105,674$ & $-111,150$ & $-140,954$ & $-167,543$ & $-204,288$ \\
\hline Gastos de administración & & $-39,290$ & $-39,290$ & $-39,290$ & $-39,290$ & $-39,290$ \\
\hline Otros gastos de RRHH & & $-10,000$ & $-10,000$ & $-10,000$ & $-10,000$ & $-10,000$ \\
\hline Gastos de responsabilidad social empresarial & & $-36,000$ & $-36,000$ & $-36,000$ & $-36,000$ & $-36,000$ \\
\hline Gastos de ventas & & $-123,983$ & $-137,355$ & $-156,816$ & $-195,832$ & $-257,722$ \\
\hline Escudo fiscal & & 27,225 & & & & \\
\hline Inversiones & 151,252 & & & & & \\
\hline Liquidación de IGV & & $-98,652$ & $-108,946$ & $-127,751$ & $-135,909$ & $-151,587$ \\
\hline Impuesto a la renta & & $-15,679$ & $-25,219$ & $-29,321$ & $-32,423$ & $-36,123$ \\
\hline Pago de dividendos & & 0 & $-9,543$ & $-15,430$ & $-21,453$ & $-41,604$ \\
\hline = FLUJO DE CAJA LIBRE (FCL) & & 118,495 & 105,680 & 122,679 & 105,855 & 101,734 \\
\hline Elabortación propia & & & & & & \\
\hline
\end{tabular}

\subsection{Políticas de aplicación de resultados}

Se ha definido como política de repartición de dividendos que se ejecutará a razón de los siguientes valores porcentuales de la tabla 7.8.

Tabla 7.8: Repartición de utilidades

\begin{tabular}{|c|c|c|c|c|c|}
\hline & Año 1 & Año 2 & Año 3 & Año 4 & Año 5 \\
\hline Utilidad retenida inicial & 0 & 36,583 & 85,885 & 138,871 & 193,073 \\
\hline (+) Utilidad del ejercicio & 36,583 & 58,845 & 68,416 & 75,655 & 84,288 \\
\hline (=) Utilidad distribuible & 36,583 & 95,428 & 154,301 & 214,526 & 277,361 \\
\hline - Dividendos & & 9,543 & 15,430 & 21,453 & 41,604 \\
\hline Utiliad retenida final & 36,583 & 85,885 & 138,871 & 193,073 & 235,757 \\
\hline Dividendos a repartir & $0 \%$ & $10 \%$ & $10 \%$ & $10 \%$ & $15 \%$ \\
\hline Elaboración propia & & & & & \\
\hline
\end{tabular}

7.10 Tasa de descuento del accionista

A continuación, en La tabla $\mathrm{N}^{\circ} 7.9$ se calcula la tasa de descuento del accionista empleando la tasa del riesgo país, la rentabilidad exigida por los accionistas, así como el riesgo de negocios nuevos en países emergentes, entre los principales. 
Tabla 7.9 Cálculo de la tasa de descuento de los accionistas

Tasa de descuentos en US\$̦:

$\mathrm{td}$ us\$ $=\mathrm{T} \mathrm{Lr}+\mathrm{B}^{*}(\mathrm{tm}-\mathrm{T} \mathrm{Lr})+$ Riesgo país

Tasa libre de riesgo (bonos del tesoro norteamericano a 5 años 1928-2017)

Beta desapalancado del sector inmobiliario de EEUU

Elaboración propia

\subsection{Indicadores de Rentabilidad representativos}

A continuación, en la tabla 7.10 desarrollaremos los indicadores de rentabilidad del Valor Actual Neto (VAN) y la Tasa Interna de Retorno (TIR).

\begin{tabular}{|c|c|c|c|c|c|c|}
\hline \multicolumn{7}{|c|}{ Tabla 7.10 Determinación del VAN y TIR } \\
\hline & Inversión & Añ॰ 1 & Año 2 & Año 3 & Año 4 & Año 5 \\
\hline$=$ Utilidad Neta & $-128,180$ & 118,495 & 105,680 & 122,679 & 105,855 & 101,734 \\
\hline \multicolumn{7}{|l|}{ Inversión incial } \\
\hline$N($ años) & 5 & & & & & \\
\hline COK & $17.66 \%$ & & & & & \\
\hline VAN & S/ $224,525.55$ & & & & & \\
\hline TIR & $84.89 \%$ & & & & & \\
\hline \multirow{2}{*}{\multicolumn{4}{|c|}{$\begin{array}{l}\text { VAN financiero al costo de capital del } \\
\text { accionista }\end{array}$}} & & & \\
\hline & & & & & & \\
\hline \multicolumn{3}{|c|}{ Tasa Interna de Retorno TIR } & $84.89 \%$ & & & \\
\hline \multicolumn{2}{|c|}{ Elaboración propia } & & & & & \\
\hline
\end{tabular}

La tasa Interna de retorno es $84.89 \%$ que puede ser alta, pero es una característica de los negocios de servicio.

También desarrollamos los cálculos del Retorno sobre el capital (ROE), el Retorno sobre los activos (ROA) y el Retorno sobre la Inversión (ROI); todo esto lo presentamos en la Tabla $\mathrm{N}^{\circ}$ 7. 11 . 


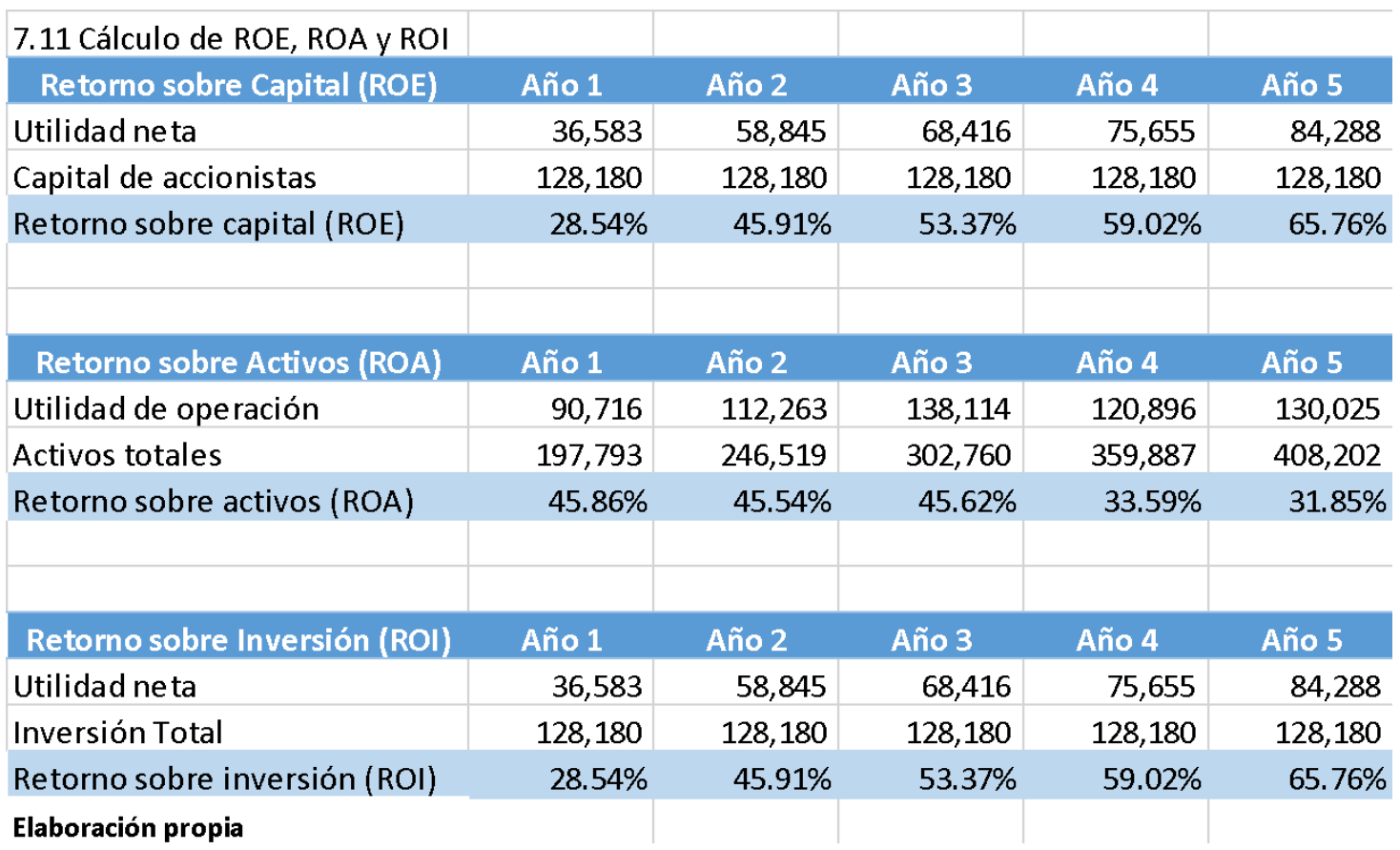

Finalmente, en la tabla $\mathrm{N}^{\circ} 7.12$ mostramos el punto de equilibrio, es decir las ventas necesarias para que se cubran todos los costos y gastos, pero no genere utilidad.

\begin{tabular}{|l|r|r|r|r|r|}
\hline 7.12 Cálculo del Punto de Equilibrio & & & & \\
& Año 1 & Año 2 & Año 3 & Año 4 & Año 5 \\
\hline Ventas (V) & 750,000 & 818,000 & 928,800 & $1,027,000$ & $1,173,000$ \\
\hline Costos Variables (CV) & 0 & 0 & 0 & 0 & 0 \\
\hline Margen de contribución & 750,000 & 818,000 & 928,800 & $1,027,000$ & $1,173,000$ \\
\hline Costos Fijos (CF) & $-697,738$ & $-733,936$ & $-831,063$ & $-918,922$ & $-1,052,589$ \\
\hline Punto de Equilibrio (PE) (capacitación conductores) & 665 & 699 & 791 & 875 & 1,002 \\
\hline $\begin{array}{l}\text { Punto de Equilibrio (PE) en Soles } \\
\text { Elaboración propia }\end{array}$ & 697,738 & 733,936 & 831,063 & 918,922 & $1,052,589$ \\
\hline
\end{tabular}

\subsection{Análisis de viabilidad y Rentabilidad financiera}

Como se ha podido evidenciar en las tablas anteriores, podemos afirmar que el proyecto es viable financieramente, teniendo como Valor Actual Neto S/. 224,525, por ende, cubriendo la inversión, costos y gastos propios de la operación.

Por otro lado, tenemos que la Tasa Interna de Retorno obtenida es de $84.89 \%$ un valor positivo que nos indica la viabilidad positiva del negocio.

Podemos concluir con estos 2 indicadores que es viable el proyecto.

\subsection{Análisis de Riesgo}


Para el análisis de los riesgos nos basaremos en el análisis FODA que se realizó, porque es ahí donde hemos identificado los riesgos y amenazas que se pueden presentar y podrían variar nuestros resultados, esto ya ha sido considerado en la estimación de las ventas mostrado en la Tabla $\mathrm{N}^{\circ}$ 7.6. Cabe señalar que, para este cálculo, hemos sido conservadores por ser un tipo de negocio nuevo. Con esto mitigamos los riesgos económicos que se pudiesen presenta una vez iniciado el proyecto.

\subsection{Análisis por escenarios}

Los escenarios presentados en la Tabla $\mathrm{N}^{\circ} 7.13$, muestra los escenarios más probables, el escenario pesimista y el escenario optimista, cada uno con las modificaciones en el número de servicios de capacitación vendidos por empresa. 


\begin{tabular}{|c|c|c|c|c|c|}
\hline \multicolumn{6}{|c|}{ Tabla 7.13: Proyección de ventas - Escenario más probable } \\
\hline & Año 1 & Año 2 & Año 3 & Año 4 & Año 5 \\
\hline Ventas por capacitación ( $\mathrm{N}^{\circ}$ conductores) & 600 & 660 & 756 & 840 & 960 \\
\hline Precio de venta por día (S/.) & 50 & 50 & 50 & 50 & 50 \\
\hline Número de días & 21 & 21 & 21 & 21 & 21 \\
\hline Sub-total & 630,000 & 693,000 & 793,800 & 882,000 & $1,008,000$ \\
\hline Asesoría a empresa de transporte (horas) & 2,400 & 2,500 & 2,700 & 2,900 & 3,300 \\
\hline Preciode venta(S/.) & 50 & 50 & 50 & 50 & 50 \\
\hline Sub-total & 120,000 & 125,000 & 135,000 & 145,000 & 165,000 \\
\hline Ingresospor ventas & 750,000 & 818,000 & 928,800 & $1,027,000$ & $1,173,000$ \\
\hline Ingresospor ventas (Inc. IGV) & 885,000 & 965,240 & $1,095,984$ & $1,211,860$ & $1,384,140$ \\
\hline \multicolumn{6}{|l|}{ Escen ario optimista } \\
\hline & Año 1 & Año 2 & Año 3 & Año 4 & Año 5 \\
\hline Ventas por capacitación ( $\mathrm{N}^{\circ}$ conductores) & 690 & 759 & 859 & 966 & 1,104 \\
\hline Precio de venta por día (S/.) & 50 & 50 & 50 & 50 & 50 \\
\hline Número de días & 21 & 21 & 21 & 21 & 21 \\
\hline Sub-total & 724,500 & 796,950 & 912,870 & $1,014,300$ & $1,159,200$ \\
\hline Asesoría a empresa de transporte (horas) & 2,400 & 2,500 & 2,700 & 2,900 & 3,300 \\
\hline Precio de venta (S/.) & 50 & 50 & 50 & 50 & 50 \\
\hline Sub-total & 120,000 & 125,000 & 135,000 & 145,000 & 165,000 \\
\hline Ingresos por ventas & 844,500 & 921,950 & $1,047,870$ & $1,159,300$ & $1,324,200$ \\
\hline Ingresos por ventas (Inc. IGV) & 996,510 & $1,087,901$ & $1,236,487$ & $1,367,974$ & $1,562,556$ \\
\hline \multicolumn{6}{|l|}{ Escen ario más pesimista } \\
\hline & Año 1 & Año 2 & Año 3 & Año 4 & Año 5 \\
\hline Ventas por capacitación ( $\mathrm{N}^{\circ}$ conductores) & 540 & 594 & 680 & 756 & 864 \\
\hline Precio de venta por día (S/.) & 50 & 50 & 50 & 50 & 50 \\
\hline Número de días & 21 & 21 & 21 & 21 & 21 \\
\hline Sub-total & 567,000 & 623,700 & 714,420 & 793,800 & 907,200 \\
\hline Asesoría a empresa de transporte (horas) & 2,400 & 2,500 & 2,700 & 2,900 & 3,300 \\
\hline Precio de venta (S/.) & 50 & 50 & 50 & 50 & 50 \\
\hline Sub-total & 120,000 & 125,000 & 135,000 & 145,000 & 165,000 \\
\hline Ingresospor ventas & 687,000 & 748,700 & 849,420 & 938,800 & $1,072,200$ \\
\hline Ingresospor ventas (Inc. IGV) & 810,660 & 883,466 & $1,002,316$ & $1,107,784$ & $1,265,196$ \\
\hline Elaboración propia & & & & & \\
\hline
\end{tabular}

\section{15 Principales riesgos del proyecto (cualitativos)}

Los principales riesgos del proyecto que se pueden presentar son:

- La falta de pago por parte de los clientes de los servicios brindados.

- Nueva reglamentación impuesta por el Ministerio de Transportes y Comunicaciones que nos impidan operar.

- El incremento de costos por una elevación abrupta de la inflación. 
Si bien estos riesgos se pueden presentar, han sido considerados a la hora de desarrollar la evaluación financiera para que el proyecto siga viable.

\subsection{Plan de contingencia y disolución}

El plan de contingencias que hemos considerado es no incrementar el precio de venta por los primeros cinco años. Aun así, como una acción que mitigue cualquier variación no considerada que se pueda presentar está el incremento del precio de venta de nuestro servicio; además, sería coherente porque un proveedor que te de un servicio con un precio de venta, por ejemplo, de dos años sin ningún tipo de ajuste en el precio, sería fácil de sustentar básicamente por la inflación presentada en esos dos años. 


\section{CONCLUSIONES}

- Luego de un análisis integral del proyecto podemos afirmar que es viable no solo en la evaluación económica, sino también en el impacto que puede tener en la sociedad, reduciendo el número de muertes por accidentes de tránsito en el transporte de carga y transporte de pasajeros.

- Existe una necesidad en los empresarios de transporte de carga y pasajeros que no está cubierta o está cubierta parcialmente. Este proyecto busca cubrirla para reducir no solo los accidentes, sino los costos de operación como combustible, cuidado de la unidad y establecer estándares seguros de manejo.

- El desconocimiento por parte de los conductores sobre la gestión que se debe realizar a la hora de conducir un vehículo pesado o de pasajeros tiene una brecha alta por cubrir y este proyecto también aportará a ello.

- Las labores que hace el estado peruano para capacitar a los conductores sobre manejo seguro no son las suficientes para concientizar a los conductores de carga y omnibuses.

- Finalmente, con este trabajo, queremos también realizar un apoyo social concientizando a los conductores de empresas de mototaxis que circulan por las Panamericanas Sur, Norte y Carretera central; y en muchos casos, son los motivos que originan los accidentes muchas veces con fatalidades. 


\section{REFERENCIAS}

Carreño, Adolfo (2011) Logística de la A a la Z. 1era Ed. Lima : PUCP, Fondo Editorial

Defensoría del Pueblo (2017). Recuperado de http://www.defensoria.gob.pe/

Diario Oficial El Peruano (2017), Recuperado de http://www.elperuano.pe/

Diario Oficial El Peruano (2017), Recuperado de http://www.elperuano.pe/

Instituto Nacional de Estadística e Informática (2017). Recuperado de https://www.inei.gob.pe/

Instituto Nacional de Estadística e Informática (2017). Recuperado de https://www.inei.gob.pe/

Ministerio de Transportes y Comunicaciones - Oficina General de Planificación y Presupuesto (2017). Recuperado de http://www.mtc.gob.pe/

Ministerio de Transportes y Comunicaciones - Oficina General de Planificación y Presupuesto (2017). Recuperado de http://www.mtc.gob.pe/

Organización Internacional del Trabajo (2017), Industria del transporte y el almacenamiento, Capítulo 102, D - INSHT Instituto Nacional de Seguridad e Higiene en el Trabajo.

Policía Nacional del Perú (2016). Recuperado de https://www.pnp.gob.pe/

Superintendencia de Transporte Terrestre de Personas, Carga y Mercancías (2017). Recuperado de http://www.sutran.gob.pe/

Superintendencia de Transporte Terrestre de Personas, Carga y Mercancías (2017). Recuperado de http://www.sutran.gob.pe/ 
ANEXOS 


\section{ANEXO I: Perfiles y funciones del personal}

\section{$\underline{\text { Gerente General }}$}

Funciones:

- Definir el precio de los servicios

- Controlar los KPIs de la operación

- Controlar los estados financieros de la compañía

- Realizar el contacto inicial con los clientes

Perfil:

- Ingeniero industrial, ingeniero mecánico o administrador con maestría en administración de negocios o logística

- Diez años de experiencia en el rubro transportes y seguridad vial

- Mínimo tres años de experiencia en gerencia general

Gerente de Operaciones

Funciones:

- Controlar el cumplimiento de lo ofrecido al cliente en las fechas y costos definidos

- Negociar con los clientes potenciales el servicio a realizar

- Participar y controlar periódicamente en la evaluación de conductores en ruta con el fin de mejorar el servicio.

- Aplicar el Mentoring al coordinador y supervisores con el fin de instruirlos en las diferentes etapas de aprendizaje de su desempeño laboral.

- Analizar, proponer y controlar los KPIs con el fin de identificar problemas y proponer mejoras en la gestión

- Aprobar el ingreso del coordinador de conductores, supervisores y conductores técnicos.

Perfil:

- Ingeniero industrial, ingeniero mecánico o administrador con maestría en administración de negocios o logística

- Diez años de experiencia en el rubro transportes y seguridad vial

\section{$\underline{\text { Coordinador de conductores }}$}


Funciones:

- Controlar y actualizar los parámetros de manejo del conductor

- Aprobar los itinerarios para cada ruta

- Implementar en los clientes el comité de investigación de accidentes con el fín de obtener mejores prácticas en seguridad

- Evaluar en el proceso de reclutamiento a los supervisores y conductores técnicos.

Perfil:

- Ingeniero industrial, ingeniero mecánico

- Cinco años de experiencia en el rubro transportes y seguridad vial

\section{$\underline{\text { Supervisor }}$}

Funciones:

- Realizar la supervisión de la operación

- Proponer los itinerarios por rutas

- Realizar la logística necesaria para que las operaciones se desarrollen de manera adecuada.

- Compras necesarias para el personal del área

Perfil:

- Ingeniero industrial o técnico en mecánica

- Un año de experiencia en el rubro transportes y/o seguridad vial

\section{$\underline{\text { Conductor técnico }}$}

Funciones:

- Realizar la capacitación y evaluación a los conductores

- Emitir reportes por cada conductor

- Informar nuevas oportunidades en capacitación

Perfil:

- Diez años de experiencia en el transporte de pasajeros y/o carga.

- Licencia AIII

$\underline{\text { Jefe administrativo }}$

Funciones:

- Responsable de un adecuado proceso de reclutamiento

- Garantizar el pago oportuno al personal 
- Controlar la correcta facturación a los clientes

- Control de pago a proveedores

- Supervisión a la empresa que realiza los registros y pagos contables de la empresa.

Perfil:

- Ingeniero industrial, administrador o contador con maestría en administración de negocios

- Cinco años de experiencia laboral con conocimiento de contabilidad, planillas y recursos humanos.

\section{$\underline{\text { Responsable de reclutamiento }}$}

Funciones:

- Responsable de un adecuado reclutamiento de personal

- Evaluación del clima laboral de manera anual

Perfil:

- Licenciado en psicología

- Experiencia de dos años en reclutamiento de personal

$\underline{\text { Responsable de planillas }}$

Funciones:

- Responsable de la correcta preparación de las planillas de pago del personal

Perfil:

- Licenciado en contabilidad

- Mínimo tres años en experiencia en la elaboración de planillas de pagos.

\section{Asistente contable}

Funciones:

- Proceso de facturación de los servicios realizados

- Control de facturas por pagar

Perfil:

- Técnico en contabilidad

- Mínimo un año en procesos de facturación 
$\underline{\text { Asistente }}$

Funciones:

- Preparación de reportes a gerencia

- Realizar tareas asignadas por el gerente de operaciones.

Perfil:

- Estudiante de ingeniería industrial de los últimos ciclos 


\title{
ANEXO II: formato de entrevista a profundidad
}

\author{
GUIA DE PREGUNTAS PARA LA ENTREVISTA EN \\ PROFUNDIDAD PARA EL SERVICIO DE CAPACITACION A \\ CONDUCTORES DE TRANSPORTE TERRESTRE
}

Nombre:-

Puesto:

Organización:

Cantidad de vehículos: Tipo de transporte:

Fecha;

1. Cantidad de Accidentes o indicadores en seguridad

2. Cual ha sido su comportamiento de costos el su organizacion

3.- Necesidad de capacitación de sus conductores

4.- Necesidades de asesoria en su organizacion

5.-Satisfaccion de los clientes

6. Qub necesidades tiene su empresa para un mayor crecimiemto 


\section{ANEXO III: RESULTADO DE LAS ENTREVISTAS A PROFUNDIDAD}

\section{¿Están de acuerdo con el servicio}

propuesto?
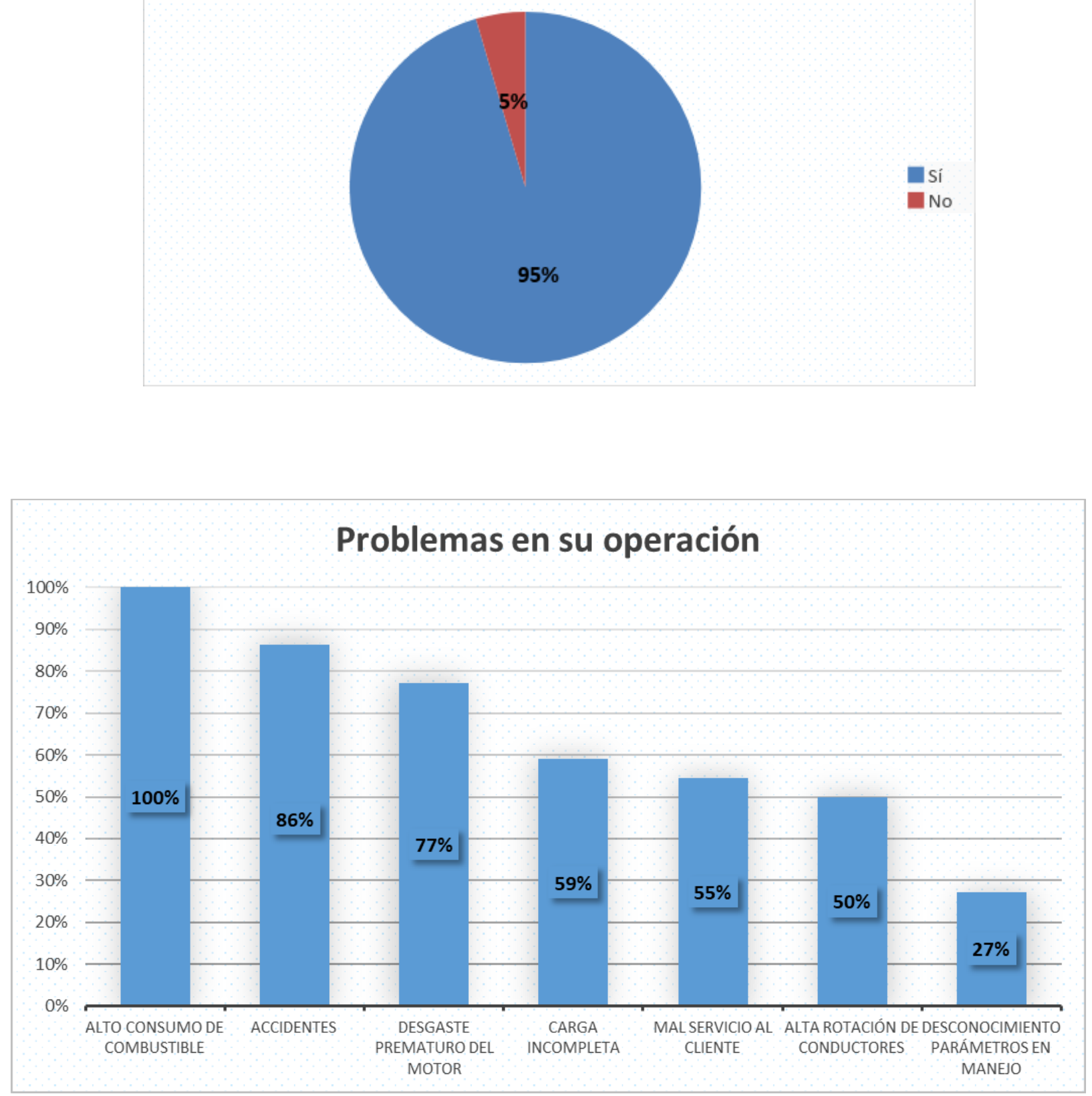


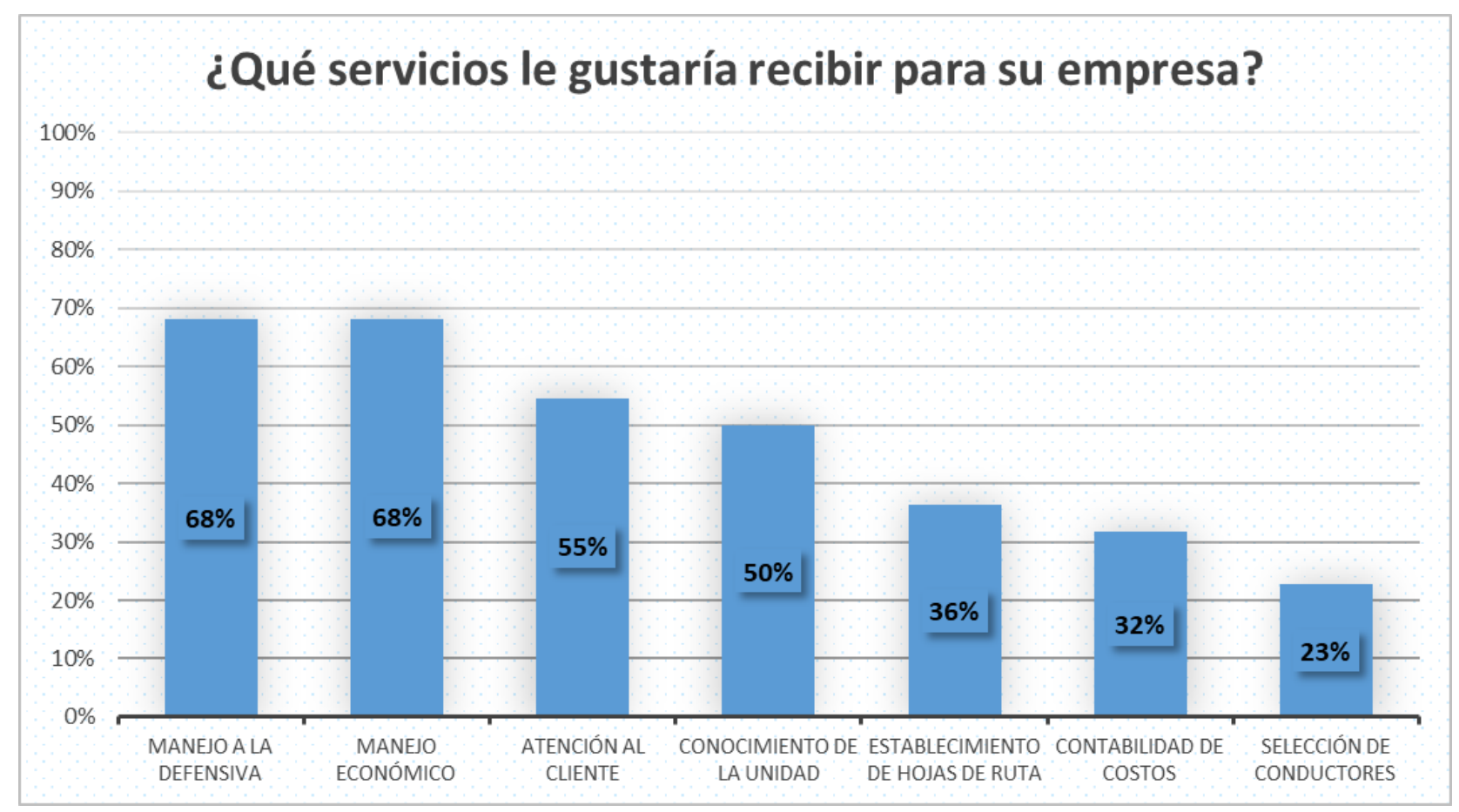

